\title{
Melatonin alleviates heat-induced damage of tomato seedlings by balancing redox homeostasis and modulating polyamine and nitric oxide biosynthesis
}

Mohammad Shah Jahan ${ }^{1,2+} \mathbb{D}^{\text {, Sheng Shu }}{ }^{1+}$, Yu Wang ${ }^{1}$, Zheng Chen ${ }^{1}$, Mingming He ${ }^{1}$, Meiqi Tao ${ }^{1}$, Jin Sun ${ }^{1}$ and Shirong Guo ${ }^{1 *}$

\begin{abstract}
Background: Melatonin is a pleiotropic signaling molecule that plays multifarious roles in plants stress tolerance. The polyamine (PAs) metabolic pathway has been suggested to eliminate the effects of environmental stresses. However, the underlying mechanism of how melatonin and PAs function together under heat stress largely remains unknown. In this study, we investigated the potential role of melatonin in regulating PAs and nitric oxide (NO) biosynthesis, and counterbalancing oxidative damage induced by heat stress in tomato seedlings.

Results: Heat stress enhanced the overproduction of reactive oxygen species (ROS) and damaged inherent defense system, thus reduced plant growth. However, pretreatment with $100 \mu \mathrm{M}$ melatonin (7 days) followed by exposure to heat stress $(24 \mathrm{~h})$ effectively reduced the oxidative stress by controlling the overaccumulation of superoxide $\left(\mathrm{O}_{2}{ }^{-}\right)$and hydrogen peroxide $\left(\mathrm{H}_{2} \mathrm{O}_{2}\right)$, lowering the lipid peroxidation content (as inferred based on malondialdehyde content) and less membrane injury index (MII). This was associated with increased the enzymatic and non-enzymatic antioxidants activities by regulating their related gene expression and modulating the ascorbate-glutathione cycle. The presence of melatonin induced respiratory burst oxidase $(R B O H)$, heat shock transcription factors A2 (HsfA2), heat shock protein 90 (HSP90), and delta 1-pyrroline-5-carboxylate synthetase (P5CS) gene expression, which helped detoxify excess ROS via the hydrogen peroxide-mediated signaling pathway. In addition, heat stress boosted the endogenous levels of putrescine, spermidine and spermine, and increased the PAs contents, indicating higher metabolic gene expression. Moreover, melatonin-pretreated seedlings had further increased PAs levels and upregulated transcript abundance, which coincided with suppression of catabolic-related genes expression. Under heat stress, exogenous melatonin increased endogenous NO content along with nitrate reductase- and NO synthase-related activities, and expression of their related genes were also elevated.
\end{abstract}

Conclusions: Melatonin pretreatment positively increased the heat tolerance of tomato seedlings by improving their antioxidant defense mechanism, inducing ascorbate-glutathione cycle, and reprogramming the PAs metabolic and NO biosynthesis pathways. These attributes facilitated the scavenging of excess ROS and increased stability of the cellular membrane, which mitigated heat-induced oxidative stress.

Keywords: Melatonin, Heat stress, Polyamines, NO biosynthesis, Redox, AsA-GSH cycle, Tomato

\footnotetext{
* Correspondence: srguo@njau.edu.cn

${ }^{\dagger}$ Mohammad Shah Jahan and Sheng Shu contributed equally to this work.

${ }^{1}$ Key Laboratory of Southern Vegetable Crop Genetic Improvement in

Ministry of Agriculture, College of Horticulture, Nanjing Agricultural

University, Nanjing 210095, People's Republic of China

Full list of author information is available at the end of the article
}

(c) The Author(s). 2019 Open Access This article is distributed under the terms of the Creative Commons Attribution 4.0 International License (http://creativecommons.org/licenses/by/4.0/), which permits unrestricted use, distribution, and

reproduction in any medium, provided you give appropriate credit to the original author(s) and the source, provide a link to the Creative Commons license, and indicate if changes were made. The Creative Commons Public Domain Dedication waiver (http://creativecommons.org/publicdomain/zero/1.0/) applies to the data made available in this article, unless otherwise stated. 


\section{Background}

Global warming has led to climate change, including heat stress and these changes considerate as a major threat for worldwide crop production [1]. Heat stress can cause misfolds or disorganized cellular homeostasis because of excess reactive oxygen species (ROS) accumulation, distorted protein structure, impeded protein synthesis, and overall cell division and growth disruption from reduced water content [2-4]. Heat shock-induced oxidative damage occurs as a result of excess formation of singlet oxygen $\left({ }_{1} \mathrm{O}^{2}\right)$, superoxide radical $\left(\mathrm{O}_{2}{ }^{-}\right)$, hydrogen peroxide $\left(\mathrm{H}_{2} \mathrm{O}_{2}\right)$, and hydroxyl radical $\left(\mathrm{OH}^{*}\right)$ under heat stress [5]; this leads to overproduction of malondialdehyde (MDA) and thus reduces membrane stability, permeability, and mobility, and impairs protein membrane polymerization $[6,7]$. As a sessile organism, in an unfavorable environment, plants develop an inherent antioxidative defense strategy to detoxify excess ROS, which helps to protect them from oxidative damage [8]. This efficient anti-oxidative defense mechanism consists of different enzymatic antioxidants, such as superoxide dismutase (SOD), catalase (CAT), peroxidase (POD), ascorbate peroxidase (APX), glutathione reductase (GR), monodehydroascorbate reductase (MDHAR), and dehydroascorbate (DHAR), and non-enzymatic antioxidants, such as ascorbate (AsA), glutathione (GSH), carotenoids, and phenols [2, 9, 10]. Additionally, heat-shock proteins (HSPs) play vital roles in ROS scavenging [11], because heat stress induces APX and CAT production [12]. Moreover, heat shock transcription factors A2 (HsfA2) plays a key role in the regulation of expression of heat-shock proteins, ascorbate peroxidase 2 and galactinol synthase 1 and 2 under hightemperature challenged [13].

Melatonin (N-acetyl-5-methoxytryptamine) is a naturally occurring low-molecular-weight multi-regulatory molecule that exists in all living organisms, including plants and animals $[14,15]$. Since its detection in plants, scientists' curiosity regarding melatonin has increased, because of its diversified biological role as a plant master regulator and defensive roles in capricious environmental conditions, such as extreme temperatures, salinity, drought, heavy metals, UV radiation, and oxidative stress [15-18]. Melatonin also accelerates seed germination [19], influences root and plant architecture [20], enhances growth vitality, ameliorates leaf senescence [21], regulates nitrogen metabolism [21], and alters physiological processes by inducing differential gene expression [16]. The most important function of melatonin is ROS detoxification through the production of free radicle scavengers $\left(\mathrm{H}_{2} \mathrm{O}_{2}, \mathrm{O}_{2}{ }^{\cdot-}\right)$ and modulation of both antioxidant enzyme activity and concentration [22, 23]. Rodriguez et al. [24] reported that pre-treated melatonin protects oxidative damage in cucumber through melatonin-mediated redox signaling pathways. Under both dark and light conditions, melatonin increases APX and
CAT activity, and elevates AsA and GSH content; the AsA-GSH cycle also helps to reduce the dark-induced senescence $[12,25]$. There is lack of research on how melatonin protects seedlings from possible damage caused by thermal stress. Consequently, the aim of this research was to elucidate melatonin's mode of action.

Polyamines (PAs) are essential stress response biomolecules; they are small molecular weight nitrogenous compounds that exist ubiquitously in plants, mostly as putrescine (Put), spermidine (Spd), and spermine (Spm) [26]. PAs possess a wide variety of functions, including plant morphogenesis, reproductive stimulation, and delayed leaf senescence, and they play key roles against abiotic stresses, such as extreme temperature (high and low), salt, drought, heavy metals, osmotic stress, ultraviolet radiation stress, and submerged stress [27, 28]. Additionally, PAs have a cationic charge that helps uphold membrane integrity, assists smooth enzyme function, and protects DNA, RNA, and protein structure. Therefore, plant physiological, biochemical, and molecular activities are enhanced through interactions with nucleic acids, proteins, and phospholipids [29]. Ke et al. [28] determined that supplemental melatonin alleviates salinity stress in wheat seedlings by regulating PAs metabolism. Melatonin increases iron-deficiency tolerance through increased accumulation of PA-mediated nitric oxide (NO) [30]. Shi et al. [31] noted that the PAs metabolic system also changed under oxidative stress conditions with melatonin pretreatment in Bermuda grass. Moreover, melatonin increased Put and Spd levels in carrot suspension cells, which helped reduce cold-induce apoptosis [32]. Additionally, melatonin pretreatment alleviated chilling stress in harvested peach fruits [33] and cucumber seedlings [34] which are closely related to PAs metabolism. These research findings revealed that melatonin may play critical roles in capricious environments by mediating PAs metabolism. Alternatively, the signaling molecule NO functions as a mediator of PAs metabolism and plant hormones, and also triggers NO biosynthesis [35]. However, until now, how melatonin regulates PAs metabolism have not been entirely understood. We hypothesize that melatonin may be associated with PAs via the NO biosynthesis pathway, thus helping plants cope with high-temperature challenges. Correlations between melatonin biosynthesis and PAs metabolism, and their underlying mechanisms could provide a novel insight that can help to promote plant production and protection.

\section{Result}

Melatonin improved morphological parameters in tomato seedling under heat stress

Fresh weight (FW) and dry weight (DW) of shoots and roots significantly decreased in high-temperature 
treatment seedlings, especially root FW and DW (Table 1). Shoot and root FW were reduced by around 30 and $12 \%$, respectively, under heat stressed seedlings compared to normal growth conditions. Conversely, exogenous melatonin mitigated temperature-induced inhibition of growth components and facilitated better growth.

\section{Melatonin controlled the overaccumulation of ROS in heat stressed tomato seedlings}

To investigate if melatonin alleviates heat stress-induced oxidative stress, we first detected $\mathrm{H}_{2} \mathrm{O}_{2}$ and $\mathrm{O}_{2}{ }^{\cdot-}$ generation in tomato leaves by histochemical staining. As shown in Fig. 1a, b, we observed deeper blue staining, which indicates $\mathrm{O}_{2}{ }^{--}$production, and acute brown staining, which denotes $\mathrm{H}_{2} \mathrm{O}_{2}$ production, on the leaf surface of high temperature-stressed tomato seedlings. Conversely, the differences among the other treated seedlings were less in their leaf blades, which indicates that melatonin inhibits ROS overproduction under stress conditions.

To evaluate the ROS accumulation trends under melatonin and/or heat stress, we further examined the generation rates of $\mathrm{O}_{2}{ }^{\cdot-}$ and $\mathrm{H}_{2} \mathrm{O}_{2}$ in tomato leaves (Fig. 1c, d). Relative to the control, sharp increases in $\mathrm{O}_{2}{ }^{\cdot-}$ and $\mathrm{H}_{2} \mathrm{O}_{2}$ production were observed in the leaf tissues upon subjected to heat stress. Under heat stress, $\mathrm{H}_{2} \mathrm{O}_{2}$ and $\mathrm{O}_{2}{ }^{--}$contents increased by 32 and $137 \%$, respectively, compared with the control seedlings. By contrast, application of melatonin increased the heat-stress tolerance of seedlings by reducing the formation rates of $\mathrm{H}_{2} \mathrm{O}_{2}$ and $\mathrm{O}_{2}{ }^{-}$in leaf tissue by 15 and $36 \%$, respectively, compared with the plants grown solely in the hightemperature environment.

\section{Melatonin maintained cellular membrane integrity in tomato leaves under heat stress}

High temperatures destroyed tomato seedling leaves cellular membranes as indicated by MII (80\%) and the higher accumulation of MDA content (45\%) compared with the control (Fig. 2). Application of $100 \mu \mathrm{M}$ melatonin was more effective for overcoming harsh impacts of heat stress, as shown by a substantial reduction of
MII (29\%) and lower MDA concentration (16\%) compared with untreated heat-stressed plants.

\section{Melatonin enhanced proline metabolism and RWC in tomato seedlings under heat stress}

Heat-stressed plants induced elevated proline biosynthesis that was $158 \%$ greater compared with the corresponding control (Fig. 3a). The melatonin-pretreatment combined with heat-stressed seedlings showed a maximum proline content that was $212 \%$ greater than that of control. To verify this, we further quantified the gene expression of P5CS, which is responsible for proline biosynthesis. The P5CS expression pattern was substantially upregulated (1.62-fold) in heat-stressed seedlings compared with the control plants. Melatonin pretreatment in heat-stressed seedlings further markedly upregulated P5CS expression by 6 -folds in contrast with seedlings that were grown only heat-stressed conditions (Fig. 3b).

For RWC, in respect to normal plants, high-temperature challenge seedlings considerably decreased the RWC by $10 \%$; supplemental melatonin application curtailed a significant amount of water loss from their tissues, and these plants contained 7\% more RWC than the untreated heatstressed seedlings (Fig. 3c).

\section{Melatonin balanced the antioxidant defense system in tomato seedlings under heat stress}

To evaluate the role of melatonin in oxidative stress remediation, we investigated the activities of antioxidant enzymes upon exposure to heat stress (Fig. 4). Under heat stress, SOD activity substantially declined and was 1.89-fold lower than in the control; alternatively, SOD activity significantly increased and was 1.29-fold higher in plants with melatonin pretreatment under high temperatures than untreated heatstressed seedlings (Fig. 4a). Heat stress caused a marked decrease of $41 \%$ in CAT activity in leaves compared with normally grown leaves; melatonin-pretreated heat-stressed seedlings had upwards of $36 \%$ greater in CAT activity than untreated heat-stressed leaves (Fig. 4b). Melatonin-pretreated heat-stressed seedlings had dramatically increased POD activity (by 23\%) in contrast with untreated heat-

Table 1 Effects of melatonin on the morphology of heat stress exposed tomato seedlings

\begin{tabular}{lllll}
\hline Treatments & $\begin{array}{l}\text { Shoot fresh weight } \\
\left(\mathrm{g} \mathrm{plant}^{-1}\right)\end{array}$ & $\begin{array}{l}\text { Shoot dry weight } \\
\left(\mathrm{g} \mathrm{plant}^{-1}\right)\end{array}$ & $\begin{array}{l}\text { Root fresh weight } \\
\left(\mathrm{g} \mathrm{plant}^{-1}\right)\end{array}$ & $\begin{array}{l}\text { Root dry weight } \\
\left(\mathrm{g} \mathrm{plant}^{-1}\right)\end{array}$ \\
\hline CK & $8.65 \pm 0.17 \mathrm{a}$ & $0.88 \pm 0.05 \mathrm{a}$ & $2.30 \pm 0.26 \mathrm{~b}$ & $0.16 \pm 0.01 \mathrm{ab}$ \\
MT & $8.90 \pm 0.15 \mathrm{a}$ & $0.91 \pm 0.06 \mathrm{a}$ & $4.17 \pm 0.13 \mathrm{a}$ & $0.21 \pm 0.02 \mathrm{a}$ \\
HT & $6.03 \pm 0.18 \mathrm{~b}$ & $0.47 \pm 0.02 \mathrm{c}$ & $2.04 \pm 0.15 \mathrm{~b}$ & $0.12 \pm 0.05 \mathrm{~b}$ \\
MT +HT & $8.03 \pm 0.16 \mathrm{a}$ & $0.65 \pm 0.03 \mathrm{~b}$ & $4.04 \pm 0.21 \mathrm{a}$ & $0.20 \pm 0.02 \mathrm{a}$ \\
\hline
\end{tabular}

Data represent as a mean of standard deviation (SD) of three replications. Different letters indicate significant differences according to Tukey's HSD test at $P \leq 0.05$ CK: Control, MT: $100 \mu \mathrm{M}$ melatonin, $\mathrm{HT}$ : High temperature $\left(42^{\circ} \mathrm{C}\right), \mathrm{MT}+\mathrm{HT}: 100 \mu \mathrm{M}$ melatonin + high temperature $\left(42^{\circ} \mathrm{C}\right)$ 

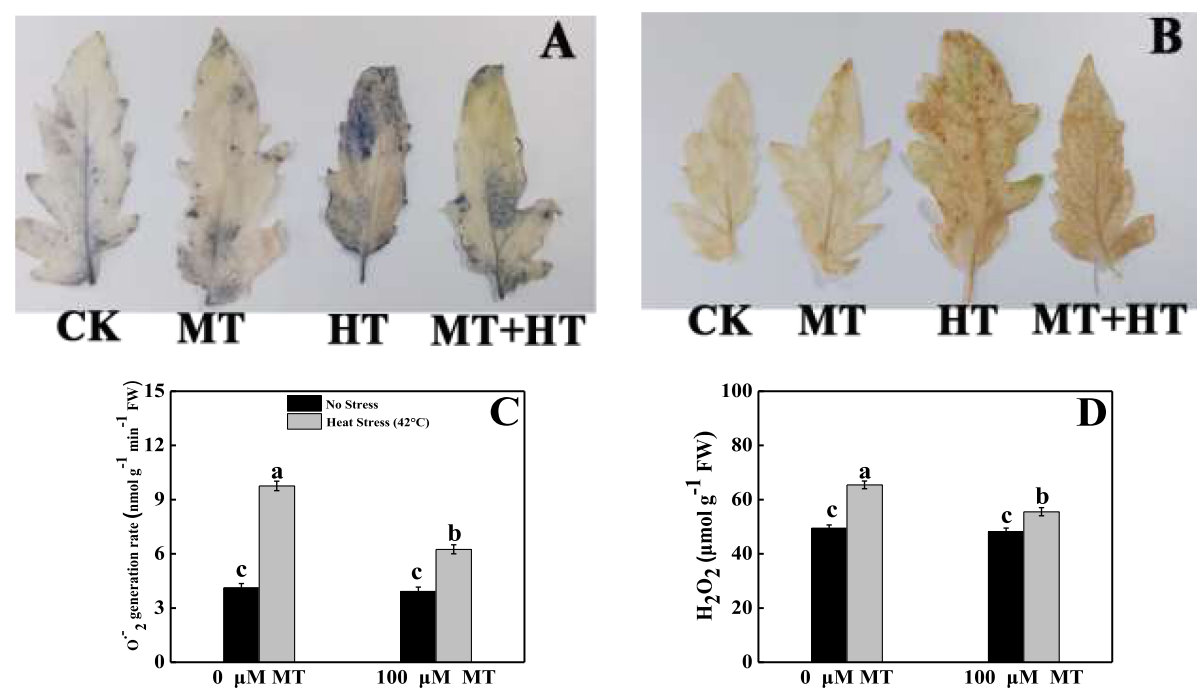

Fig. 1 Effects of Melatonin $(100 \mu \mathrm{M})$ on accumulation of $(\mathbf{A})$ superoxide ion $\left(\mathrm{O}_{2}{ }^{-}{ }^{-}\right)$, (B) hydrogen peroxide $\left(\mathrm{H}_{2} \mathrm{O}_{2}\right),(\mathbf{C})$ generation of superoxide ion $\left(\mathrm{O}_{2}^{-{ }^{-}}\right)$and $(\mathbf{D})$ content of hydrogen peroxide $\left(\mathrm{H}_{2} \mathrm{O}_{2}\right)$ in leaves of tomato seedlings in presence or absence of high temperature $\left(42^{\circ} \mathrm{C}\right)$ stress. $\mathrm{CK}$ : Control; MT: $100 \mu \mathrm{M}$ melatonin; HT: High temperature $\left(42^{\circ} \mathrm{C}\right)$; MT + HT: $100 \mu \mathrm{M}$ melatonin + high temperature $\left(42^{\circ} \mathrm{C}\right)$. Data represent as a mean of standard deviation (SD) of three replications. Different letters indicate significant differences according to Tukey's HSD test at $P \leq 0.05$

stressed seedlings; however, relative to control plants, POD activity sharply declined in untreated heat-stressed seedlings (29\%, Fig. 4c). Under heat stress, APX activity decreased by $60 \%$ compared with the control, whereas, melatonin pretreatment in heat-stressed seedlings resulted in $230 \%$ greater APX activity than that of untreated heatstressed seedlings (Fig. 4d).

\section{Melatonin induced the AsA-GSH cycle and homeostasis in tomato seedlings under heat stress}

As displayed in Fig. 5a, AsA content was markedly increased by $47 \%$ after heat stress in contrast to the control plants. Moreover, in response to normal seedlings, AsA content was further increased by $62 \%$ in melatonin-pretreated heat-stressed seedlings. Under exposure to heat stress, the GSH content was remarkably increased (168\%) in contrast to the corresponding control seedlings (Fig. 5b).
Alternatively, melatonin-pretreated heat-stressed seedlings had $28 \%$ greater GSH content with respect to the untreated heat-stressed seedlings.

There were no significant differences in GR activity among the treatments except in the untreated heatstressed seedlings (Fig. 6a). However, GR activity sharply decreased by $45 \%$ in thermal-stressed plants with respect to the control seedlings. By contrast, when plants treated with melatonin followed by high-temperature exposure showed upregulation of GR activity by $94 \%$ than seedlings subjected to heat-stressed alone.

However, marked decreases of MDHAR and DHAR activities were observed in heat-stressed seedlings compared to other seedlings. Additionally, in respect to only heat-stressed seedlings MDHAR and DHAR enzyme contents rose by 91 and 56\%, respectively, in melatoninpretreated heat-stressed seedlings (Fig. 6b, c).
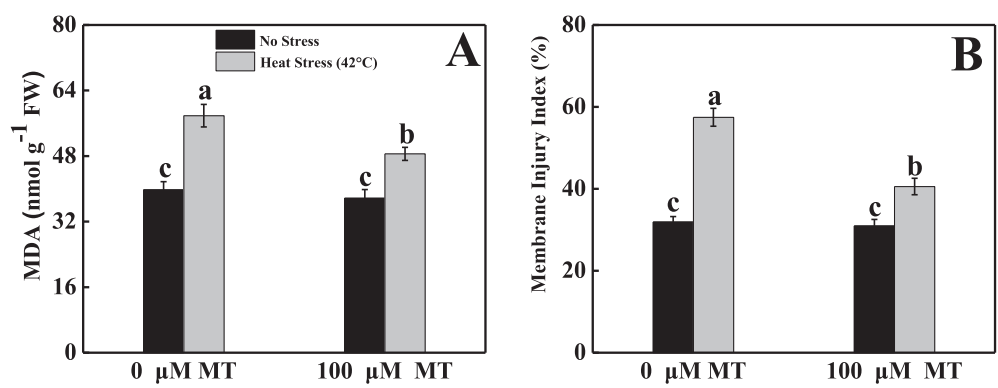

Fig. 2 Effects of Melatonin (100 $\mu$ M) on (A) malondialdehyde (MDA) content and (B) membrane injury index (MII) in leaves of tomato seedlings in presence or absence of high temperature $\left(42^{\circ} \mathrm{C}\right)$ stress. Data represent as a mean of standard deviation (SD) of three replications. Different letters indicate significant differences according to Tukey's HSD test at $P \leq 0.05$ 

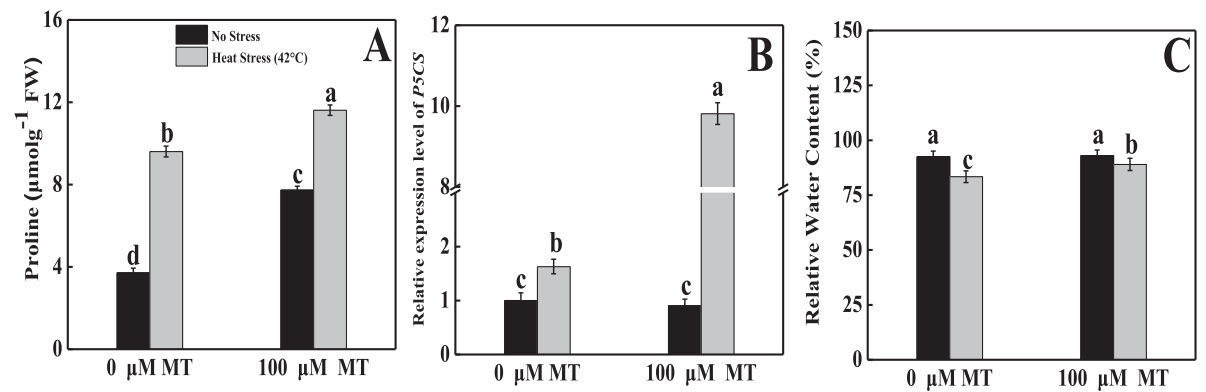

Fig. 3 Effects of Melatonin (100 $\mu \mathrm{M})$ on (A) proline content and (B) relative transcript expression of P5CS and (C) relative water content (REL) in leaves of tomato seedlings in presence or absence of high temperature $\left(42^{\circ} \mathrm{C}\right)$ stress. Data represent as a mean of standard deviation $(\mathrm{SD})$ of three replications. Different letters indicate significant differences according to Tukey's HSD test at $P \leq 0.05$

In untreated heat-stressed seedlings, the GST activity slightly decreased by around 19\% compared with the control groups. In contrast, melatonin pretreatment increased GST activity by $39 \%$ than untreated heatstressed seedlings (Fig. 6d).

\section{Melatonin modulated the transcription of enzymatic antioxidants under heat stress}

To elucidate the molecular mechanism underlying how melatonin alleviates heat stress-induced oxidative damage, the transcript levels of some key genes that encode antioxidant enzymes were assayed. The results showed that SOD (Fig. 4e), CAT (Fig. 4f), APX (Fig. 4h), and GST (Fig. 6h) gene expression levels were upregulated by 1.6-, 1.2-, 3.2-, and 1.3-fold, respectively, in response to their corresponding control groups. Alternatively, the application of exogenous melatonin upregulated SOD, CAT, POD (Fig. 4g), APX, GR (Fig. 6e), MDHAR (Fig. 6f), DHAR (Fig. 6g), and GST expression by 2.1-, 1.3-, 1.7-, 3.0-, 5.6-, 2.4-, 1.8-, and 3.4-fold, respectively, compared with untreated heat-stressed seedlings.

\section{Melatonin regulated the $\mathrm{RBOH}$ expression in tomato leaves under heat stress}

As indicated in Fig. 7a, we analyzed the tomato $R B O H$ expression level. The $R B O H$ transcript levels were prominently elevated in heat-stressed seedlings than control ones. Conversely, exogenously applied melatonin with subsequent high-temperature exposure also increased $R B O H$ expression by 1.89 -fold compared with untreated heat-stressed plants.
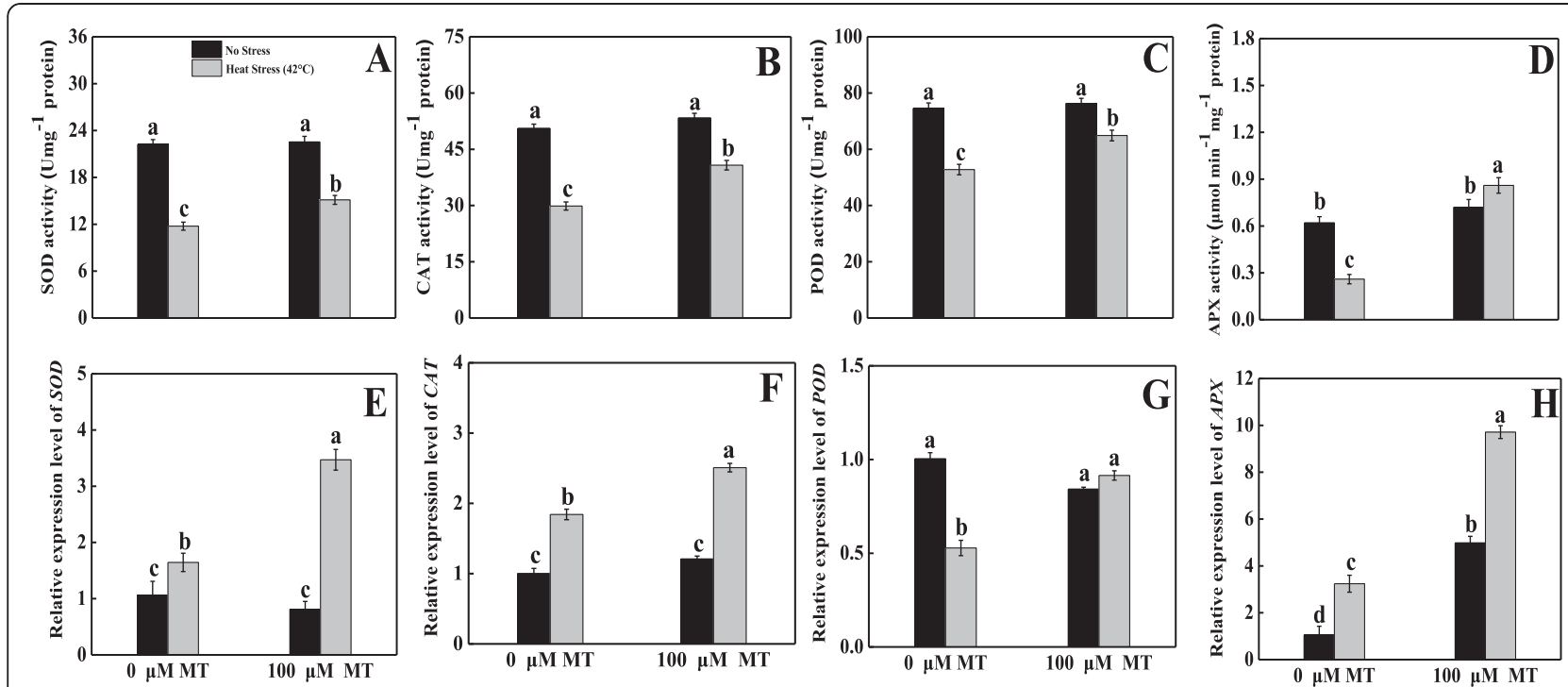

Fig. 4 Effects of Melatonin (100 $\mu \mathrm{M})$ on antioxidant enzymes activities and their related transcript expression of (A, E) superoxide dismutase (SOD), (B, F) catalase (CAT), (C, G) peroxidase (POD) and ( $\mathbf{D}, \mathbf{H})$ ascorbate peroxidase (APX) in leaves of tomato seedlings in presence or absence of high temperature $\left(42^{\circ} \mathrm{C}\right)$ stress. Data represent as a mean of standard deviation (SD) of three replications. Different letters indicate significant differences according to Tukey's HSD test at $P \leq 0.05$ 

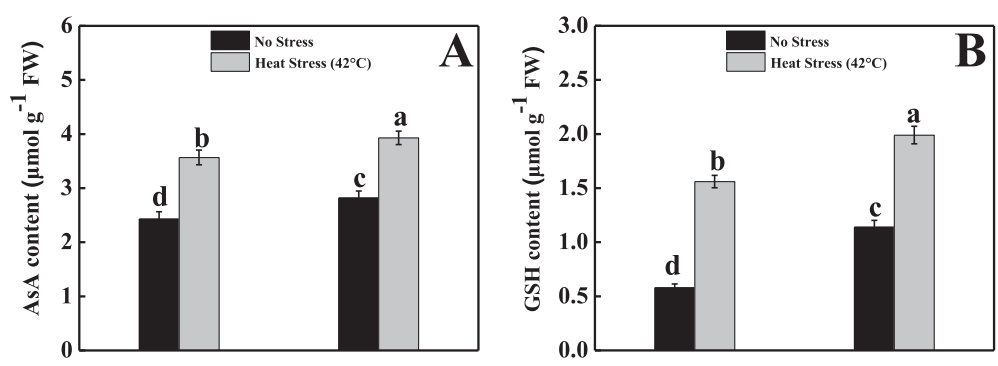

Fig. 5 Effects of Melatonin (100 $\mu \mathrm{M})$ on (A) ascorbic acid (AsA) and (B) glutathione (GSH) content in leaves of tomato seedlings in presence or absence of high temperature $\left(42^{\circ} \mathrm{C}\right)$ stress. Data represent as a mean of standard deviation (SD) of three replications. Different letters indicate significant differences according to Tukey's HSD test at $P \leq 0.05$

\section{Melatonin regulated the heat shock-related genes expression in tomato leaves under heat stress}

As shown in Fig. 7b, c, HSP9O and HsfA2 expression levels were increased by 4.1 - and 3.26-fold, respectively, in untreated heat-stressed seedlings compared with control seedlings. In contrast to untreated heat-stressed seedlings, the HSP9O and HsfA2 transcript levels were sharply upregulated by 1.29 - and 1.55 -fold, respectively, in melatonin-pretreated heat-stressed seedlings.

\section{Melatonin modulated endogenous levels of PAs and their} genes expression in tomato leaves under heat stress

We quantified endogenous free PAs accumulation to explicate how PAs and melatonin coordinate in order to eliminate the adverse effects of thermal stress. The Put,
Spd, and Spm contents significantly increased in heatstressed seedlings by $25.26,48.24$, and $24.43 \%$, respectively, compared with the control group (Fig. 8). Melatonin supplementation further increased Put by $82.52 \%$, Spd by $78.72 \%$, and Spm by $247.80 \%$ relative to their corresponding control plants.

To reveal the expression profile of PAs metabolism, we performed heatmap visualization and hierarchical cluster analysis (Fig. 9). In the presence of melatonin, the mRNA levels of PAs metabolic genes showed higher expression than control. High-temperature stress exposure with or without melatonin treatments caused upregulation of the transcript levels of the assayed genes. The $A D C 1, A D C 2$, and $O D C 1$ mRNA levels were increased in stressed seedlings, with and without melatonin,
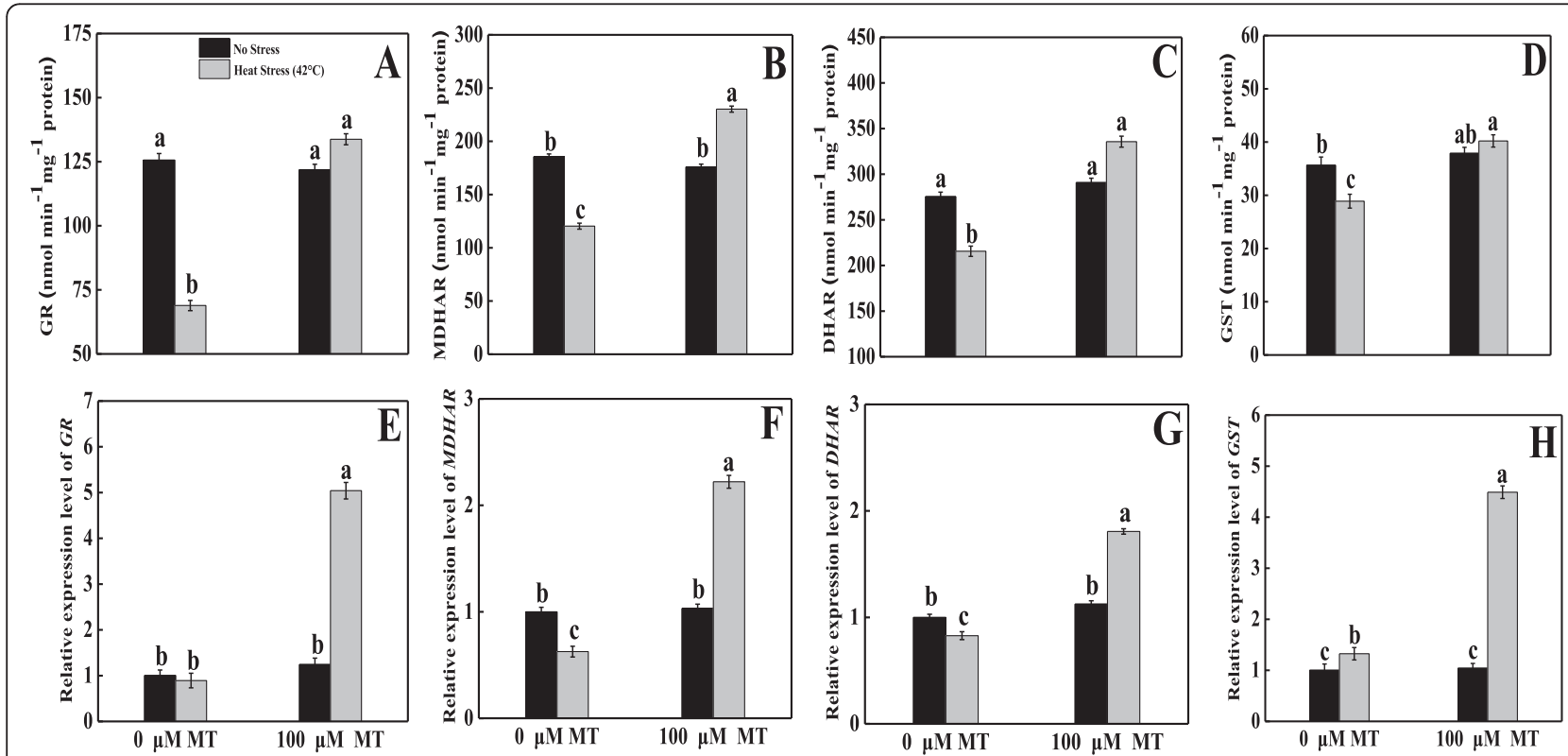

Fig. 6 Effects of Melatonin $(100 \mu M)$ on antioxidant enzymes activities and their related transcript expression of (A, E) glutathione reductase (GR), $(\mathbf{B}, \mathbf{F})$ monodehydroascorbate reductase (MDHAR), (C, G) dehydroascorbate reductase (DHAR) and (D, H) glutathione S-transferase (GST) in leaves of tomato seedlings in presence or absence of high temperature $\left(42^{\circ} \mathrm{C}\right)$ stress. Data represent as a mean of standard deviation (SD) of three replications. Different letters indicate significant differences according to Tukey's HSD test at $P \leq 0.05$ 


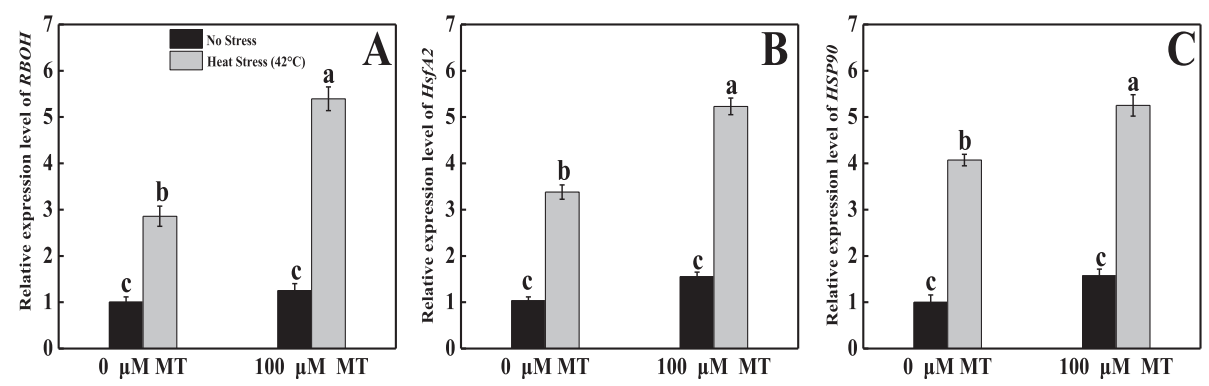

Fig. 7 Effects of Melatonin (100 $\mu \mathrm{M})$ on relative transcript expression of (A) Respiratory burst oxidase (RBOH) and (B) heat shock factor A 2 (HsfA2) (C) heat shock protein 90 (HSP9O) in leaves of tomato seedlings in presence or absence of high temperature $\left(42^{\circ} \mathrm{C}\right)$ stress. Data represent as a mean of standard deviation (SD) of three replications. Different letters indicate significant differences according to Tukey's HSD test at $P \leq 0.05$

whereas $O D C 2$ expression was downregulated in all heat-stressed seedlings compared with control seedlings. Similarly, the SAMDC1, SAMDC2, and SPMS transcript abundance also increased in response to either all heatstressed seedlings compared with control seedlings. Furthermore, in contrast to untreated heat-stressed seedlings, the SPDS1, SPDS2, SPDS3, SPDS4, and SPDS5 expression levels were also upregulated in melatoninpretreated plants. Interestingly, the PAO1 and PAO2 transcript levels were downregulated in melatonin-pretreated seedlings than untreated heat-stressed plants, which indicates that melatonin might inhibit heat-induced damage via the PAs metabolic pathway and not a catabolic process.

\section{Melatonin regulated the NO biosynthesis pathway under heat stress}

As displayed in Fig. 10, untreated heat-stressed plants released 38\% more NO than control seedlings. In contrast, melatonin pretreatment further increased the NO content in thermal-stressed tomato seedlings by approximately 205\% than control plants. NR activity increased upon exposure to high temperatures with or without melatonin applied to the seedlings. Melatonin-pretreated heat-stressed seedlings markedly increased NR activity in respect to control plants by around $218 \%$.
Alternatively, in the case of NOS-like activity, there was not significant variation between control and heat-stressed seedlings. The NOS-like activity was dramatically increased by $164 \%$ in melatonin-pretreated heat-stressed seedlings in contrast with control seedlings. The relative transcript level of NR was increased (2.6- fold) in untreated heat-stressed seedlings than control seedlings. However, NR expression was further exponentially upregulated (2.35- fold) in melatonin-pretreated heat-stressed seedlings in respect to untreated heat-stressed seedlings. However, in the case of NOS, expression was downregulated in all heat-stressed seedlings with or without melatonin pretreatment compared with the control seedlings.

\section{Discussion}

Melatonin is a pleiotropic molecule that is involved in diverse plant physiological functions, including seed morphogenesis, growth, and development; root architecture; photosynthesis; and chlorophyll pigment production; and it is a plant master regulator and defensive player in capricious environments [16]. Cellular oxidative damage is a stress marker of high-temperature stress, and $\mathrm{H}_{2} \mathrm{O}_{2}$ and $\mathrm{O}_{2}{ }^{\cdot-}$ generation, MDA content, and MII are the representative of these stress markers. Heat-stressed tomato leaves conspicuously displayed deep blue spots, which indicated that they produced more $\mathrm{O}_{2}{ }^{--}$. The leaves also had dark brown patches,
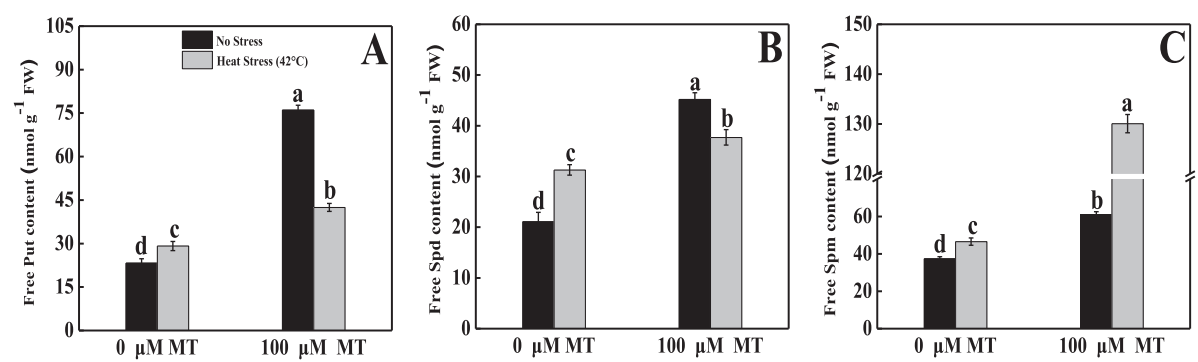

Fig. 8 Effects of Melatonin $(100 \mu \mathrm{M})$ on endogenous free polyamines content of (A) Putrescine (Put), (B) Spermidine (Spd), (C) Spermine (Spm) in leaves of tomato seedlings in presence or absence of high temperature $\left(42^{\circ} \mathrm{C}\right)$ stress. Data represent as a mean of standard deviation (SD) of three replications. Different letters indicate significant differences according to Tukey's HSD test at $P \leq 0.05$ 


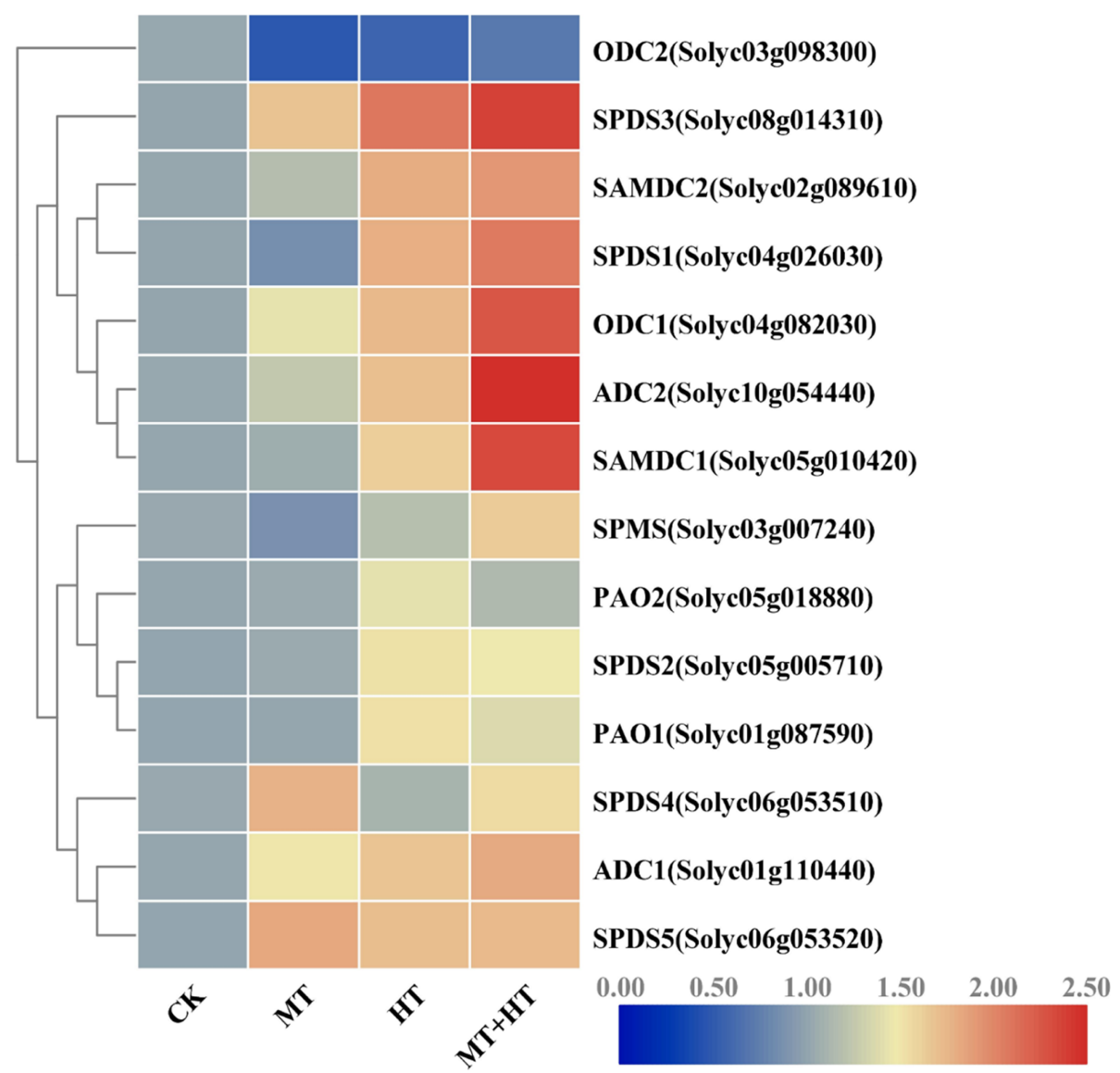

Fig. 9 Heat-map representing the relative transcript abundance of differentially expressed Polyamines genes in leaves of tomato seedlings under high temperature stress with or without melatonin pretreatment and also hierarchical cluster analysis were used. The gene expression intensity extended from blue color (low) to red color (high). CK: Control; MT: $100 \mu \mathrm{M}$ melatonin; HT: High temperature $\left(42^{\circ} \mathrm{C}\right) ; \mathrm{MT}+\mathrm{HT}$ : $100 \mu \mathrm{M}$ melatonin + high temperature $\left(42^{\circ} \mathrm{C}\right)$

which indicated greater accumulation of $\mathrm{H}_{2} \mathrm{O}_{2}$ under the same stress conditions. These staining symptoms were supported by quantification of $\mathrm{H}_{2} \mathrm{O}_{2}$, and $\mathrm{O}_{2}{ }^{--}$, which showed markedly higher generation under elevated temperatures compared with melatonin-pretreated heatstressed seedlings (Fig. 1). These findings are consistent with prior findings that melatonin decreased $\mathrm{H}_{2} \mathrm{O}_{2}$ and $\mathrm{O}_{2}{ }^{\cdot-}$ accumulation in kiwifruit [36], watermelon [37], cucumber [38], and Malus hupehensis [39]. The probable mechanism underlying this decrease may be that melatonin acts as an electron donor [40]. MDA often represents an essential stress symptom that forms through an auto-oxidative chain reaction as a result of ROS-induced bio-membrane damage [41]. However, in a capricious environment, the MII and MDA concentration are predominantly associated with each other. Plants exposed to heat stress had sharply increased MDA levels that could potentially damage the plasma membrane integrity, which elevated MII in tomato seedlings (Fig. 2). Melatonin application decreased both
MDA and MII, which is consistent with the findings of previous studies on kiwifruit [36, 42], Bermuda grass [31], and tomato [43] under various abiotic stresses. These results indicate that melatonin may be able to repair the disrupted cellular membrane and reduce heat-induced oxidative damage by balancing ROS in a high-temperature environment. HsfA2 and HSP90 are the key regulators that stimulate ROS detoxification through the $\mathrm{H}_{2} \mathrm{O}_{2}$-mediated signaling pathway and, therefore, increase plant thermo-tolerance. In this study, melatonin-pretreated tomato seedlings had upregulated HsfA2 and HSP9O expression compared with untreated heat-stressed seedlings (Fig. 7), which indicates that melatonin ameliorated the heat stressinduced oxidative damage caused by HsfA2 and HSP90 activation. A recent report also revealed that $H s f A 2$ plays roles in $\mathrm{H}_{2} \mathrm{O}_{2}$ signaling and increases heat stress memory subsistence, whereas HSP9O coordinates DNA-binding enhancement process and HSF balanced in plants exposed to heat stress, and this whole mechanism might be related to melatonin-mediated heat tolerance [22, 44-46]. 


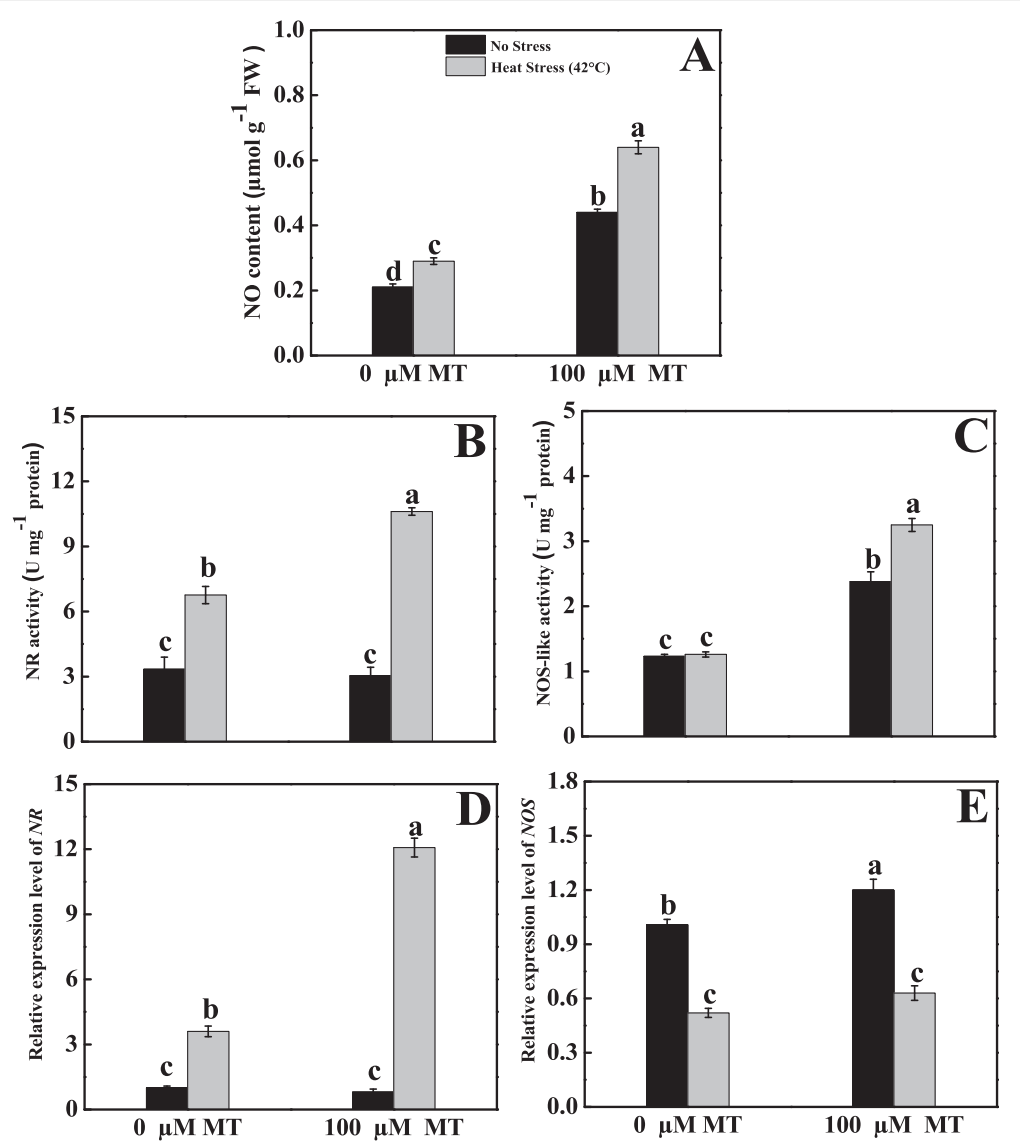

Fig. 10 Effects of Melatonin (100 $\mu \mathrm{M})$ on NO biosynthesis pathway in leaves of tomato seedlings in presence or absence of high temperature $\left(42^{\circ} \mathrm{C}\right)$ stress. A NO content, B, D NR activity and its transcript expression level, C, E NOS-like activity and its transcript level. Data represent as a mean of standard deviation (SD) of three replications. Different letters indicate significant differences according to Tukey's HSD test at $P \leq 0.05$

Melatonin is a dynamic antioxidant [47, 48] that extensively stimulates cellular redox homeostasis by enhancing the activity of enzymatic antioxidants, including SOD, CAT, POD, APX, GR, MDAR, and DHAR, and non-enzymatic antioxidants, including AsA and GSH [49-52]. Therefore, melatonin helps detoxify excess ROS, which helps plants survive under stressful conditions. We assayed enzyme activity and conducted expression analysis of antioxidant-related genes and observed that all the antioxidant-related enzymes activities were reduced under thermal stress. Conversely, melatonin-pretreated heat-stressed plants showed higher SOD, CAT, and POD activity relative to untreated heatstressed plants (Fig. 4). The first mechanism of defense against ROS in plants is through SOD, which eliminates $\mathrm{O}_{2}{ }^{\cdot-}$ by converting it into $\mathrm{O}_{2}$ and $\mathrm{H}_{2} \mathrm{O}_{2}$ [53]. In addition, CAT and POD also actively participate in scavenging $\mathrm{H}_{2} \mathrm{O}_{2}$, which they convert into $\mathrm{H}_{2} \mathrm{O}$ and $\mathrm{O}_{2}$ [54], which indicates that these enzymes have a vital role in scavenging more $\mathrm{H}_{2} \mathrm{O}_{2}$, and these and the MDA results were consistent with those of melatonin-treated kiwifruit [42], wheat [55], and tea [17].
Moreover, we speculated that heat stress elevated the proline content, upregulated the proline biosynthesis gene $(P 5 C S)$, and lowered the water content in leaves, whereas melatonin pretreatment further increased the proline level, P5CS expression, and leaf water content. This finding indicates that melatonin has the potential to help leaves maintain a higher water level and lower cellular osmotic potential (Fig. 3) by the proline biosynthesis pathway, which enhanced the plants' ability to cope with heat stress [56]; this was also supported by previous experimental results [57].

Alternatively, ascorbate is a vital antioxidant enzyme that substantially detoxifies ROS; APX and GR are also crucial enzymes in the AsA-GSH cycle. The activities of APX, MDHAR, DHAR, and GR enzymes were only decreased in heat stress-exposed seedlings, whereas melatonin pretreatment elevated the AsA content as a result of increased the activities of APX, MDHAR, DHAR, and GR enzymes under heat stress. All of these enzymes actively contributed to the AsA-GSH cycle, which converts the tiny non-enzymatic molecules AsA and GSH [58]. The AsA values depend upon 
metabolizing (APX) and recycling (MDHAR, DHAR) enzyme activity. Moreover, at the time of ROS detoxification, DHAR oxidizes GSH to GSSG. Simultaneously, GR recycles GSH. Therefore, we concluded that melatonin pretreatment might have the potential to reduce oxidative damage by inducing the AsA-GSH cycle [59, 60]. To elucidate the inherent mechanisms, we quantified the expression of several related genes. Under heat stress, $R B O H$ expression was upregulated and the expression level was further magnified in melatonin-pretreated heat-stressed plants (Fig. 7a). In melatonin-pretreated heat-stressed seedlings, the relative transcript abundance of enzymatic (SOD, CAT, POD) and non-enzymatic (APX, GR, MDHAR, DHAR, GST) antioxidant genes were upregulated (Figs. 4 and 6), which indicates that plants were more stable under heat stress because of excess ROS scavenging; these findings are consistent with those of previous research done on kiwifruit [42], watermelon [52], apple [61], and Arabidopsis [62] under various abiotic stress conditions.

PAs play a critical role in plant signaling transduction that is beneficial for counteracting the effects of different capricious environments [27]. Some previous studies determined that melatonin has a positive regulatory effects on plant development and abiotic stress (alkaline stress, cold, thermal, oxidative, and iron deficiency tolerance) management by interacting with the PAs signaling pathway $[28,63]$. Melatonin might ameliorate the thermal oxidative stress by interacting with the PAs and NO biosynthesis pathways. The exogenous application of melatonin elevated the endogenous free PAs level. Similarly, expression levels of different PAs biosynthesis genes were also upregulated in melatonin-pretreated heat-stressed seedlings. The transcript abundances of $A D C 1 / 2, S A M D C 1 / 2, S P M S$, and SPDS1/2/3/5/6 were upregulated (Fig. 9), and that of $P A O 1 / 2$ was downregulated in melatonin-pretreated heat-stressed seedlings, and these genes are associated with Put, Spd, and Spm biosynthesis. These findings indicate that melatonin and PAs metabolism have close interactions. This finding is also similar to that of previous research performed on various crops under different stresses [30, 32-34, 64]. Alam et al. [65] concluded that long-term heat-stressed seedlings treated with melatonin adjusted through the modulation of PAs metabolism.

Melatonin along with NO has the potential to combat different stress conditions through the L-arginine and PAs metabolic pathways [66]. However, the NOS and NR pathways are also regulated via PAs $[67,68]$. Our current data also highlight that the NO content, NR activity, and NOSlike activity along with the expression of their related genes were elevated in melatonin-pretreated heat-stressed tomato seedlings (Fig. 10), which indicates that melatonin triggered the NO activity [30]. Overall, melatonin enhanced mitigation of heat-induced damage through coordination with PA- and NO-mediated signaling pathways.

\section{Conclusions}

To determine how melatonin mitigated heat stress-induced adverse effects in tomato seedlings, we described a probable mechanism (Fig. 11). We observed that $100 \mu \mathrm{M}$ exogenous melatonin treatment improved the thermal tolerance of tomato seedlings by lowering $\operatorname{ROS}\left(\mathrm{H}_{2} \mathrm{O}_{2}, \mathrm{O}_{2}{ }^{\cdot-}\right.$, MDA) production, enhanced antioxidant enzyme activity, AsA-GSH cycle modulation, and upregulation of antioxidant-related gene expression. Additionally, melatonin elevates endogenous PAs via upregulation of PAs biosynthesis genes. NO content along with NR and NOS activity were also increased with melatonin supplementation. Therefore, we concluded that heat stress-induced damage was suppressed by melatonin, which coordinates with the PAs and NO biosynthesis pathways, which helps to detoxify the overaccumulated ROS. These findings provide novel insight into the cross-talk that exists among melatonin, PAs, and NO to inhibit thermal stress. To better understand this phenomenon, further investigation is needed to determine how these three molecules collectively function to alleviate the heatstress induced damage.

\section{Methods}

\section{Plant material and growth conditions}

Tomato (Solanum lycopersicum L. Cv. Hezuo 903) seeds (Shanghai Tomato Research Institute, Shanghai, China) were sorted by uniform size and then sterilized by $0.1 \%$ sodium hypochloride $(\mathrm{NaOCl})$ for $5 \mathrm{~min}$, followed by washing several times with deionized water; then, they were placed in dark conditions for $36 \mathrm{~h}$ at $28 \pm 1{ }^{\circ} \mathrm{C}$ for germination. Germinated seeds were then sown in plastic trays $(41 \times 41 \times 5 \mathrm{~cm})$ that contained a peat and vermiculite $(2: 1, \mathrm{v}: \mathrm{v})$ mixture and cultured in a growth chamber at Nanjing Agriculture University, where the environmental conditions were maintained at $28 \pm 1^{\circ} \mathrm{C}$ (day) and $19 \pm 1^{\circ} \mathrm{C}$ (night), relative humidity from 65 to $75 \%$, and $12 \mathrm{~h}$ photoperiods (PAR $300 \mu \mathrm{mol} \mathrm{m}{ }^{-2} \mathrm{~s}^{-1}$ ). After the second true leaf was fully expanded, the uniformly grown seedlings were selected and transferred into containers filled with a peat and vermiculite $(2,1, \mathrm{v}, \mathrm{v})$ mixture and watered on alternate days with fullstrength Hoagland solution.

\section{Treatment and sampling}

When the fourth true leaves were fully developed, the seedlings were divided into two sub-groups for challenge under different treatments. Melatonin was applied as described in previous experiment performed 


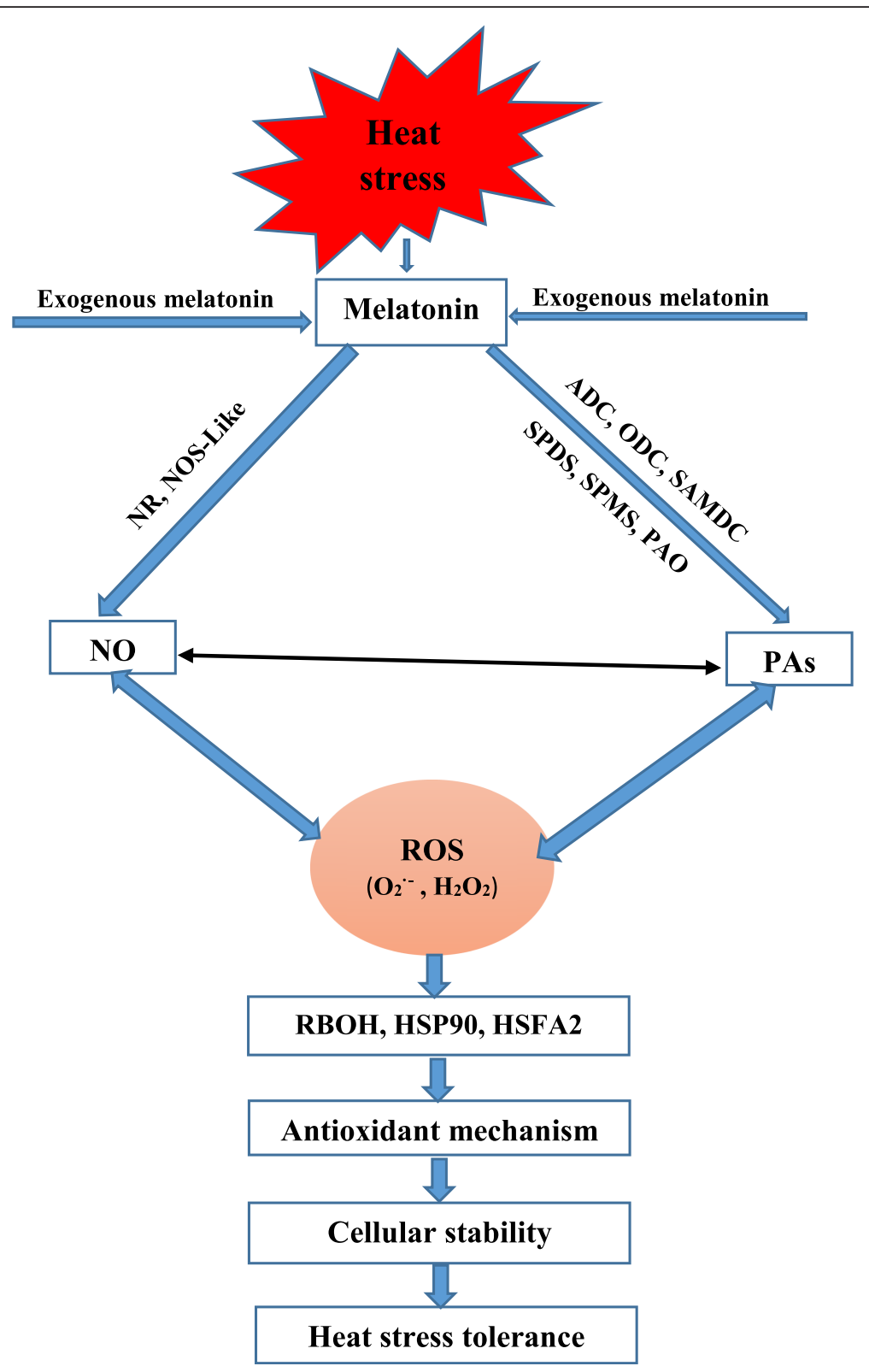

Fig. 11 The schematic representation of possible mechanism of melatonin mediated high temperature stress tolerance in tomato seedlings via the PAs and NO biosynthesis pathway. PAs: polyamines; ADC: arginine decarboxylase; ODC: ornithine decarboxylase; SPDS: spermidine synthase; SPMS: spermine synthase; SAMDC: s-adenosyl methionine decarboxylase; PAO: polyamine oxidase; NO: Nitric oxide; NR: nitrate reductase; NOS: nitric oxide synthase; ROS: reactive oxygen species; $\mathrm{H}_{2} \mathrm{O}_{2}$ : hydrogen peroxide; $\mathrm{O}_{2}^{-{ }^{-}}$: superoxide anion; $\mathrm{RBOH}$ : Respiratory burst oxidase; $\mathrm{HSFA2}$ : heat shock transcription factors A2; HSP90: heat shock protein 90

by Martinez et al. [69]. In the first sub-group, $80 \mathrm{~mL}$ of $100 \mu \mathrm{M}$ melatonin was sprayed on each tomato seedling leaves each day and for 7 days; in the second sub-group, each tomato seedling leaves were sprayed with the same volume of water. Melatonin stock solution was prepared by dissolving melatonin in $\mathrm{dd}_{2} \mathrm{O}$ with $0.01 \% \mathrm{v} / \mathrm{v}$ Tween-20 used as a surfactant. One week after treatment, half of the melatonin-treated seedlings and half of the water-sprayed seedlings were separated and exposed to a high temperature $\left(42^{\circ} \mathrm{C}\right)$ for $24 \mathrm{~h} \mathrm{[10].} \mathrm{After} 24 \mathrm{~h}$ of heat treatment, leaves were harvested for subsequent analysis and immediately stored at $-80^{\circ} \mathrm{C}$.

\section{Measurement of growth indicators}

To assess the combined effects of melatonin and heat-stressed in tomato seedlings, we measured different growth indicators such as fresh and dry weight of leaves and roots. Fresh weight of leaves and roots 
were measured by electric balance. For dry weight records plants were oven dried $\left(80^{\circ} \mathrm{C}\right.$ for $72 \mathrm{~h}$ ).

\section{Histochemical detection of $\mathrm{H}_{2} \mathrm{O}_{2}$ and $\mathrm{O}_{2}{ }^{\cdot-}$}

$\mathrm{H}_{2} \mathrm{O}_{2}$ and $\mathrm{O}_{2}{ }^{\cdot-}$ generation rate were detected using 3,3diamino benzidine (DAB) and nitro blue tetrazolium (NBT), respectively, using a previously described method [70] with minor modification. For $\mathrm{H}_{2} \mathrm{O}_{2}$ localization, stained leaves were placed in vacuum along with 0.5 $\mathrm{mg} \cdot \mathrm{mL}^{-1}$ fresh DAB solution prepared by $25 \mathrm{mM}$ Tris$\mathrm{HCl}(\mathrm{pH} 3.8)$ and kept for $12 \mathrm{~h}$ at room temperature. Brown spots appeared on the surface of leaves because of the reaction between $\mathrm{DAB}$ and $\mathrm{H}_{2} \mathrm{O}_{2}$. For $\mathrm{O}_{2}{ }^{\cdot-}$ detection, the other leaf samples were immersed with 1 $\mathrm{mg} \cdot \mathrm{mL}^{-1}$ NBT solution, which was made with $10 \mathrm{mM}$ phosphate buffer (pH 7.8), and incubated at room temperature in the dark for $12 \mathrm{~h}$. Blue spots were also present on leaves because of the reaction of NBT and $\mathrm{O}_{2}{ }^{*-}$. Both of the stained leaf samples were bleached by boiling in $95 \%$ ethanol for 20 min to remove chlorophyll. Then, the samples were placed into absolute ethanol for several hours before taking photos with a digital camera.

\section{Determination of $\mathrm{H}_{2} \mathrm{O}_{2}$ production level}

The $\mathrm{H}_{2} \mathrm{O}_{2}$ concentration in leaves was estimated by slightly modifying a method described by Velikova et al. [71]. First, $0.2 \mathrm{~g}$ leaves were homogenized with $1.6 \mathrm{~mL}$ $0.1 \%$ trichloroacetic acid (TCA) in an ice bath for 30 min and centrifuged at $12000 \times g$ for $20 \mathrm{~min}$ at $4{ }^{\circ} \mathrm{C}$. Then, $0.5 \mathrm{~mL} 0.1 \mathrm{M}$ potassium phosphate buffer ( $\mathrm{pH} 7.8$ ) and $1 \mathrm{~mL} 1 \mathrm{M}$ KI (Potassium Iodine) were added to 0.5 $\mathrm{mL}$ supernatant and kept in a dark place for $1 \mathrm{~h}$. The absorbance was measured at $390 \mathrm{~nm}$. Finally, the $\mathrm{H}_{2} \mathrm{O}_{2}$ content was quantified with a standard curve and expressed as $\mu \mathrm{mol} \mathrm{g^{-1 }}$ FW.

\section{Determination of $\mathrm{O}_{2}^{--}$production rate}

The $\mathrm{O}_{2}{ }^{-}$- generation rate was determined following the procedure reported by Nahar et al. [72] with some alterations. Briefly, $0.2 \mathrm{~g}$ leaves were homogenized with $2 \mathrm{~mL}$ $50 \mathrm{mM}$ phosphate buffer $(\mathrm{pH} 7.8)$ and centrifuged at $12000 \times g$ for $20 \mathrm{~min}$ at $4{ }^{\circ} \mathrm{C}$. Then, $0.5 \mathrm{~mL} 50 \mathrm{mM}$ phosphate buffer (pH 7.8) and $0.1 \mathrm{~mL} 10 \mathrm{mM}$ hydroxylamine hydrochloride were mixed in $0.5 \mathrm{~mL}$ supernatant and incubated at room temperature for $30 \mathrm{~min}$. After incubation, $1 \mathrm{~mL} 17 \mathrm{mM}$ sulfanilamide and $1 \mathrm{~mL}$ of $7 \mathrm{mM}$ naphthylamine were added to the mixture and incubated for $30 \mathrm{~min}$. The absorbance reading of the mixture was measured at $530 \mathrm{~nm} . \mathrm{O}_{2}{ }^{--}$production was then calculated with a standard curve of $\mathrm{NaNO}_{2}$ and expressed as nmol g-1 $\min ^{-1} \mathrm{FW}$.

\section{Membrane injury index (MII) measurement}

Membrane injury index (MII) of leaves was computed to the method outlined by Jahan et al. [10] with few modifications. Briefly, $0.5 \mathrm{~g}$ fresh leaves were thoroughly washed with deionized water, cut into small pieces, put into tubes filled with $20 \mathrm{~mL}$ deionized water, and placed at room temperature for $4-5 \mathrm{~h}$ under dark conditions in a shaker; then, the initial electrical conductivity (EC1) in the bathing solution was determined by a portable conductivity meter (DDS-307, Shanghai Precision and Scientific Instrument LTD., Shanghai, China). Subsequently, the samples were boiled at $95^{\circ} \mathrm{C}$ for $20 \mathrm{~min}$ and cooled to room temperature, and the final electrical conductivity (EC2) was measured in the bathing solution. Simultaneously, we determined the deionized water conductivity (EC0). The MII was calculated as follows:

$$
\operatorname{MII}(\%)=\frac{\mathrm{EC} 1-\mathrm{EC} 0}{\mathrm{EC} 2-\mathrm{EC} 0} \times 100
$$

\section{Lipid peroxidation measurement}

Lipid peroxidation was inferred based on MDA content in leaves, which was measured as described by Alexieva et al. [73] with slight adjustments. First, $0.2 \mathrm{~g}$ leaf samples were homogenized in a $1.6 \mathrm{~mL} 0.1 \%(\mathrm{w} / \mathrm{v}) \mathrm{TCA}$ solution and centrifuged at $4{ }^{\circ} \mathrm{C}$ for $20 \mathrm{~min}$ at $12000 \times g$. From the supernatant, a $1.0-\mathrm{mL}$ aliquot was added to $1.0 \mathrm{~mL}$ TCA containing $0.67 \% \mathrm{TBA}$; then, the sample was boiled at $95^{\circ} \mathrm{C}$ for $15 \mathrm{~min}$ and kept on ice for cooling. Subsequently, the mixture was centrifuged at $4400 \times g$ for $10 \mathrm{~min}$. Then, MDA content was measured at $532 \mathrm{~nm}$ and $600 \mathrm{~nm}$ by a spectrophotometer (Evolution 300, Thermo Fisher Scientific, Waltham, MA, USA).

\section{Proline content determination}

The proline content was evaluated following the method described by Bates et al. [74]. Fresh leaf samples $(0.2 \mathrm{~g})$ were digested in $3 \%$ sulphosalicylic acid followed by centrifugation at $12000 \times g$ for $20 \mathrm{~min}$ at $4{ }^{\circ} \mathrm{C}$. The same amount of glacial acetic acid and ninhydrin solutions were incorporated in the supernatant and incubated for $30 \mathrm{~min}$. Consequently, the sample was heated at $100^{\circ} \mathrm{C}$ for $1 \mathrm{~h}$, and $5 \mathrm{~mL}$ toluene was added after cooling. Toluene absorbance was read at $520 \mathrm{~nm}$ by a spectrophotometer (Spectronic 20D, Milton Roy, Philadelphia, PA, USA).

\section{Relative water content measurement}

The relative water content (RWC) was calculated using the method established by Barrs and Weatherley [75] with some changes. Fully developed leaves were arbitrarily detached from treated plants and immediately weighed as FW, followed by soaking in distilled water 
and incubation for $6 \mathrm{~h}$ at room temperature. Then, the excess surface water was removed with a paper towel, and the turgid weight (TW) was recorded. Leaf samples were then oven dried at $80^{\circ} \mathrm{C}$ for $72 \mathrm{~h}$ to obtain the dry weight (DW). RWC was calculated using the following equation:

$$
\mathrm{RWC}(\%)=\frac{\mathrm{FW}-\mathrm{DW}}{\mathrm{TW}-\mathrm{DW}} \times 100
$$

\section{Leaf enzymes activity assays}

Fresh leaf samples $(0.2 \mathrm{~g})$ were digested with a chilled pestle and mortar in $1.6 \mathrm{~mL} 50 \mathrm{mM}$ pre-cooled phosphate buffer ( $\mathrm{pH} 7.8$ ), and supernatants were obtained by centrifugation of the homogenate at $12000 \times g$ for 20 $\min$ at $4{ }^{\circ} \mathrm{C}$. The supernatants were then used to estimate the antioxidant enzymes activities.

SOD activity (EC 1.15.1.1) was calculated using a modified version of the protocol described by Giannopolitis and Ries [76], and Maresca et al. [77] described the procedure that was used to estimate POD (EC 1.11.1.7) activity. Briefly, a $40-\mu \mathrm{L}$ enzyme extract was added to a 3-mL reaction mixture that contained $14.5 \mathrm{mM}$ Met, $30 \mu \mathrm{M}$ EDTA- $\mathrm{Na}_{2}$ solution, $50 \mathrm{mM}$ phosphate buffer ( $\mathrm{pH} 7.8$ ), $2.25 \mathrm{mM}$ NBT solution, and $60 \mu \mathrm{M}$ riboflavin solution. The SOD content was monitored at $560 \mathrm{~nm}$. For POD activity assay, $40 \mu \mathrm{L}$ enzyme solution was mixed with a 3$\mathrm{mL}$ reaction volume that included $0.2 \mathrm{M}$ phosphate buffer (pH 6.0), $50 \mathrm{mM}$ guaiacol, and $2 \% \mathrm{H}_{2} \mathrm{O}_{2}$ solution, and absorbance was quantified at $470 \mathrm{~nm}$.

To determine catalase (CAT, EC 1.11.1.6) activity, the protocol described by Dhindsa et al. [78] was used. Briefly, a $0.1 \mathrm{~mL}$ enzyme solution was added followed by a $3-\mathrm{mL}$ reaction mixture that contained $0.15 \mathrm{M}$ phosphate buffer ( $\mathrm{pH} 7.0$ ) and $0.3 \% \mathrm{H}_{2} \mathrm{O}_{2}$ solution. The level of activity was calculated at $240 \mathrm{~nm}$.

To examine APX (EC 1.11.1.11) activity, the method described by Nakano and Asada [79] was used. Briefly, a 1.6- $\mathrm{mL}$ assay mixture that consisted of $50 \mathrm{mM}$ phosphate buffer (pH 7.0), $0.1 \mathrm{mM}$ EDTA- $\mathrm{Na}_{2}, 5 \mathrm{mM}$ AsA, and $20 \mathrm{mM} \mathrm{H}_{2} \mathrm{O}_{2}$ were added to $0.1 \mathrm{~mL}$ enzyme solution. The activity was calculated at $290 \mathrm{~nm}$.

AsA content was quantified as previously reported by Logan et al. [80]. Briefly, $0.1 \mathrm{~g}$ leaf samples were homogenized in $1.5 \mathrm{~mL} 6 \%$ pre-chilled $\mathrm{HClO}_{4}$. After grinding, the sample was centrifuged at $12000 \times g$ for $15 \mathrm{~min}$ at $4{ }^{\circ} \mathrm{C}$, and supernatant was collected for further analysis. For neutralization, $200 \mathrm{mM}$ sodium acetate buffer $(\mathrm{pH}$ 5.6) was added to the supernatant and AsA was assayed at $265 \mathrm{~nm}$; the absorbance reading was recorded before and after incubation of the supernatant in 1.5 units of AsA oxidase for $15 \mathrm{~min}$.

GSH was assayed with the protocol priorly described by Griffith [81]. Briefly, the leaf sample $(0.1 \mathrm{~g})$ was ground in $1.5 \mathrm{~mL} 5 \%$ sulfosalicylic acid, and the homogenized sample was centrifuged at $4{ }^{\circ} \mathrm{C}$ for $20 \mathrm{~min}$ at $12000 \times g$. The supernatant was neutralized with $200 \mathrm{mM}$ sodium acetate buffer ( $\mathrm{pH} 5.6)$. Then, 5, 5-dithiobis-(2nitrobenzoic acid) was incorporated for enzymatic recycling of GSH. The GSH content was calculated by recording the absorbance at $412 \mathrm{~nm}$ with a spectrometer.

MDHAR (EC 1.6.5.4) activity was determined based on the change (due to NADPH oxidation) in absorbance at $340 \mathrm{~nm}$, as previously described by Hossain et al. [82].

DHAR (EC 1.8.5.1) activity was assayed based on the change in absorbance at $265 \mathrm{~nm}$, as described by Nakano and Asada [79].

Glutathione S-transferase (GST) activity was assayed with GST detection kit (Solarbio Life Science, Beijing, China) following the manufacturer's instructions. First, fresh leaves $(0.1 \mathrm{~g})$ were ground with extraction buffer $(1 \mathrm{~mL})$ in an ice bath and homogenized by centrifugation at $4{ }^{\circ} \mathrm{C}$ for $10 \mathrm{~min}$ at $8000 \times g$ with the supernatant used for testing GST. GST activity was calculated using the molar extinction coefficient $9.6 \times 10^{3} \mathrm{Lmol}^{-1} \mathrm{~cm}^{-1}$.

Glutathione reductase (GR) activity was determined with GR detection kit (Solarbio Life Science, Beijing, China) following the manufacturer's instructions. Briefly, $0.1 \mathrm{~g}$ leaf tissue was taken and homogenized in $1 \mathrm{~mL}$ extraction solution in an ice bath and centrifuged at $10000 \times g$ for $10 \mathrm{~min}$ at $4{ }^{\circ} \mathrm{C}$, and the supernatant was used to determine GR activity. To calculate GR, $6.22 \times 10^{3} \mathrm{~L}$ $\mathrm{mol}^{-1} \mathrm{~cm}^{-1}$ was used as the extinction coefficient.

Nitrate reductase (NR) activity was measured with NR detection kit (Solarbio Life Science, Beijing, China) following the manufacturer's instructions. First, $0.1 \mathrm{~g}$ fresh leaf samples were gently washed and the water was removed from the leaf surface. Samples were incubated for $2 \mathrm{~h}$ in work solution under dark condition in room temperature and then kept at $-20^{\circ} \mathrm{C}$ for $30 \mathrm{~min}$. Then, samples were taken, ground in an ice bath with $1 \mathrm{~mL}$ extract solution, and centrifuged at $4000 \times g$ for $10 \mathrm{~min}$; the supernatant was used to determine NR activity.

Nitric oxide synthase (NOS) activity was assayed by NOS detection kit (Solarbio Life Science, Beijing, China) following the manufacturer's instructions.

NO content was quantified using NO detection kit (Solarbio Life Science, Beijing, China) according to the manufacturer's protocol.

\section{Protein extraction}

The protein content was determined using Bovine serum albumin (BSA) as the standard following the method described by Bradford [83].

\section{Determination of endogenous free polyamines}

Endogenous free polyamines content were assayed as the approaches reported by Shen et al. [84] with minor 
modifications. Briefly, $0.5 \mathrm{~g}$ leaf tissue was homogenized in $5 \%(\mathrm{v} / \mathrm{v})$ cold perchloric acid and incubated on ice for $1 \mathrm{~h}$. Then, homogenates were centrifuged for $20 \mathrm{~min}$ at $12000 \times g$ and the upper supernatant was used to determine the free PAs. A $0.7 \mathrm{~mL}$ aliquot was reacted with $1.4 \mathrm{~mL} \mathrm{NaOH}(2 \mathrm{~N})$ and $15 \mu \mathrm{L}$ benzoyl chloride, and then gently vortexed the mixer and incubated for $30 \mathrm{~min}$ at $37^{\circ} \mathrm{C}$. Later, to stop the reaction, $2 \mathrm{~mL}$ saturated $\mathrm{NaCl}$ was added to the solution. To extract benzoyl PAs, $2 \mathrm{~mL}$ cold diethyl ether was mixed into the solution, which was then centrifuged at $3000 \times g$ for $5 \mathrm{~min}$. The extracted benzoyl PAs were evaporated to dryness and then re-dissolved in $1 \mathrm{~mL}$ of $64 \%(\mathrm{v} / \mathrm{v})$ methanol. To separate and analyze the PAs content, we used UHPLC (Ultimate 3000, Thermo Scientific, San Jose, CA, USA) with a C18 reversed-phase column at a flow rate of $0.8 \mathrm{~mL} \mathrm{~min}^{-1}$.

\section{Total RNA extraction and quantitative real-time PCR analysis}

Total RNA was extracted from $0.1 \mathrm{~g}$ tomato leaves tissues using the RNAsimple Total RNA Kit (TIANGEN, Beijing, China) according to the manufacturer's instructions. One microgram of total RNA was reverse-transcribed into cDNA using a SuperScript First-strand Synthesis System for quantitative real-time PCR based on the manufacturer's instructions (Takara, Tokyo, Japan). The gene-specific primers were designed using DNA sequences from the NCBI database (https://www. ncbi.nlm.nih.gov/), and Sol Genomics Network (solge nomics.net) and the primer pair sequences are listed in Additional file 1: Table S1. Real-time PCR was performed on a StepOnePlus ${ }^{\mathrm{TM}}$ Real-Time PCR System (Applied Biosystems, Foster City, CA, USA) with ChamQ Universal SYBR qPCR Master Mix (Vazyme Biotech Co., Ltd., Nanjing, China). The total reaction system volume was $20 \mu \mathrm{L}$, which consisted of $10 \mu \mathrm{L}$ ChamQ SYBR qPCR Master Mix (2×), 0.4 $\mu \mathrm{L}$ ROX reference dye $1(50 \times), 2 \mu \mathrm{L}$ template cDNA $(10 \times), 0.8 \mu \mathrm{L}$ each specific primer $(10 \mu \mathrm{M})$, and $6 \mu \mathrm{L}$ sterilized $\mathrm{ddH}_{2} \mathrm{O}$. Three biological replicates were performed for each reaction and the cycling conditions were as follows: $95^{\circ} \mathrm{C}$ for $5 \mathrm{~min}$, followed by 40 cycles of denaturation at $95^{\circ} \mathrm{C}$ for $15 \mathrm{~s}$ and annealing at $60^{\circ} \mathrm{C}$ for 1 min, and a final extension at $95^{\circ} \mathrm{C}$ for $15 \mathrm{~s}$. Relative expression was calculated using the $2^{-\Delta \Delta \mathrm{Ct}}$ formula [85], and the mRNA expression level was normalized against actin (used as an internal control) and compared.

\section{Statistical analysis}

At least five independent biological replicates were performed for each treatment, and three replicates were performed for the whole experiment. All of the data were statistically analyzed with SPSS 20.0 (SPSS Inc., Chicago, IL, USA). One way analysis of variance was performed, and statistically significant differences among the treatments were determined using Tukey's honest significant difference test at $P<0.05$. A transcript expression heatmap was created using the TBtools statistic package. Origin Pro 8.0 was used to make graphs.

\section{Additional files}

\section{Additional file 1: Table S1. List of primers used for qRT-PCR assays.} (DOCX 29 kb)

\section{Abbreviations \\ ${ }_{1} \mathrm{O}^{2}$ : Singlet oxygen; ADC: Arginine decarboxylase; APX: Ascorbate peroxidase; AsA: Ascorbate; BSA: Bovine serum albumin; CAT: Catalase; DHAR: Dehydroascorbate; DNA: Deoxy ribo nucleic acid; EC: Electrical conductivity; GR: Glutathione reductase; GSH: Glutathione; GST: Glutathione S-transferase; $\mathrm{H}_{2} \mathrm{O}_{2}$ : Hydrogen peroxide; HsfA2: Heat shock transcription factors A2; HSP90: Heat shock protein 90; HSPs: Heat shock proteins; MDA: Malondialdehyde; MDHAR: Monodehydroascorbate reductase; MII: Membrane injury index; NO: Nitric oxide; NOS: Nitric oxide synthase; NR: Nitrate reductase; $\mathrm{O}_{2}^{-{ }^{-}}$: Superoxide anion; ODC: Ornithine decarboxylase; $\mathrm{OH}$ : Hydroxyl radical; P5CS: Delta 1-pyrroline-5-carboxylate synthetase; PAO: Polyamine oxidase; PAs: Polyamines; POD: Peroxidase; PUT: Putrescine; $\mathrm{RBOH}$ : Respiratory burst oxidase; RNA: Ribo nucleic acid; ROS: Reactive oxygen species; RWC: Relative water content; SAMDC: S-adenosyl methionine decarboxylase; SOD: Superoxide dismutase; SPD: Spermidine; \\ SPDS: Spermidine synthase; SPM: Spermine; SPMS: Spermine synthase}

\section{Acknowledgments \\ We thanks to Dr.Mallory Eckstut for critical reading and editing of this manuscript.}

\section{Authors' contributions}

SRG conceived and designed the experiments. MSJ conducted the experiments and wrote the manuscript. ZC, MH, MT contributed supplied materials, data collection, analysis tools and analyzed the data. YW, SS and JS supervised and revised the manuscript. All authors reviewed and approved the manuscript.

\section{Funding}

This work was financially supported by the National Natural Science Foundation of China (31672199 and 31801902), the China Earmarked Fund for Modern Agro-industry Technology Research System (CARS-23-B12), and Jiangsu Province Scientific and Technological Achievements into Special Fund (BE2017701). The supporters did not play any role in the design, collection, analysis, interpretation of the relevant data, or in writing the manuscript.

\section{Availability of data and materials}

The datasets generated and analyzed during the current study are available from the corresponding author on reasonable request.

Ethics approval and consent to participate Not applicable.

Consent for publication

Not applicable.

\section{Competing interests}

The authors declare that they have no competing of interest.

\section{Author details}

${ }^{1}$ Key Laboratory of Southern Vegetable Crop Genetic Improvement in Ministry of Agriculture, College of Horticulture, Nanjing Agricultural University, Nanjing 210095, People's Republic of China. ${ }^{2}$ Department of Horticulture, Faculty of Agriculture, Sher-e-Bangla Agricultural University, Dhaka 1207, Bangladesh. 
Received: 31 May 2019 Accepted: 27 August 2019

Published online: 07 October 2019

\section{References}

1. Ohama N, Sato H, Shinozaki K, Yamaguchi-Shinozaki K. Transcriptional regulatory network of plant heat stress response. Trends Plant Sci. 2017; 22(1):53-65.

2. Hasanuzzaman M, Nahar K, Alam M, Roychowdhury R, Fujita M. Physiological, biochemical, and molecular mechanisms of heat stress tolerance in plants. Int J Mol Sci. 2013;14(5):9643-84.

3. Lazar D, Murch SJ, Beilby MJ, Al Khazaaly S. Exogenous melatonin affects photosynthesis in characeae Chara australis. Plant Signal Behav. 2013:8(3):e23279.

4. Salvucci ME, Crafts-Brandner SJ. Relationship between the heat tolerance of photosynthesis and the thermal stability of rubisco activase in plants from contrasting thermal environments. Plant Physiol. 2004;134(4):1460-70.

5. Vasseur F, Pantin F, Vile D. Changes in light intensity reveal a major role for carbon balance in Arabidopsis responses to high temperature. Plant Cell Environ. 2011;34(9):1563-76.

6. Mishkind M, Vermeer JE, Darwish E, Munnik T. Heat stress activates phospholipase D and triggers PIP2 accumulation at the plasma membrane and nucleus. Plant J. 2009;60(1):10-21.

7. Narayanan S, Tamura PJ, Roth MR, Prasad PV, Welti R. Wheat leaf lipids during heat stress: I. high day and night temperatures result in major lipid alterations. Plant Cell Environ. 2016;39(4):787-803.

8. Mittler R, Vanderauwera S, Suzuki N, Miller G, Tognetti VB, Vandepoele K, Gollery M, Shulaev V, Van Breusegem F. ROS signaling: the new wave? Trends Plant Sci. 2011;16(6):300-9.

9. Allakhverdiev SI, Kreslavski VD, Klimov W, Los DA, Carpentier R, Mohanty P. Heat stress: an overview of molecular responses in photosynthesis. Photosyn Res. 2008;98(1-3):541.

10. Jahan MS, Wang Y, Shu S, Zhong M, Chen Z, Wu J, Sun J, Guo S. Exogenous salicylic acid increases the heat tolerance in tomato (Solanum lycopersicum $\mathrm{L}$ ) by enhancing photosynthesis efficiency and improving antioxidant defense system through scavenging of reactive oxygen species. Sci Hortic 2019;247:421-9.

11. Li H, LIU SS, Yi CY, Wang F, Zhou J, Xia XJ, Shi K, Zhou YH, Yu JQ. Hydrogen peroxide mediates abscisic acid-induced HSP 70 accumulation and heat tolerance in grafted cucumber plants. Plant Cell Environ. 2014;37(12):2768-80.

12. Ahammed GJ, Xu W, Liu A, Chen S. Endogenous melatonin deficiency aggravates high temperature-induced oxidative stress in Solanum lycopersicum L. Environ Exp Bot. 2019;161:303-311.

13. Nishizawa A, Yabuta Y, Yoshida E, Maruta T, Yoshimura K, Shigeoka S. Arabidopsis heat shock transcription factor A2 as a key regulator in response to several types of environmental stress. Plant J. 2006:48(4):535-47.

14. Arnao MB, Hernández-Ruiz J. Melatonin and its relation-ship to plant hormones. Ann Bot. 2018:121(2):195-207.

15. Wang Y, Reiter RJ, Chan Z. Phytomelatonin: a universal abiotic stress regulator. J Exp Bot. 2017;69(5):963-74.

16. Arnao MB, Hernández-Ruiz J. Melatonin: a new plant hormone and/or a plant master regulator? Trends Plant Sci. 2018;24(1):38-48.

17. Li X, Wei J-P, Scott E, Liu J-W, Guo S, Li Y, Zhang L, Han W-Y. Exogenous melatonin alleviates cold stress by promoting antioxidant defense and redox homeostasis in Camellia sinensis L. Molecules. 2018;23(1):165.

18. Wei $Y$, Chang $Y$, Zeng H, Liu G, He C, Shi H. RAV transcription factors are essential for disease resistance against cassava bacterial blight via activation of melatonin biosynthesis genes. J Pineal Res. 2018;64(1):e12454.

19. Tiryaki I, Keles $H$. Reversal of the inhibitory effect of light and high temperature on germination of Phacelia tanacetifolia seeds by melatonin. J Pineal Res. 2012;52(3):332-9.

20. Arnao MB, Hernández-Ruiz J. Melatonin promotes adventitious-and lateral root regeneration in etiolated hypocotyls of Lupinus albus L. J Pineal Res. 2007:42(2):147-52.

21. Zhang R, Sun Y, Liu Z, Jin W, Sun Y. Effects of melatonin on seedling growth, mineral nutrition, and nitrogen metabolism in cucumber under nitrate stress. J Pineal Res. 2017;62(4):e12403.

22. Shi H, Tan DX, Reiter RJ, Ye T, Yang F, Chan Z. Melatonin induces class A1 heat-shock factors (HSFA 1s) and their possible involvement of thermotolerance in Arabidopsis. J Pineal Res. 2015;58(3):335-42.
23. Rodriguez C, Mayo JC, Sainz RM, Antolín I, Herrera F, Martín V, Reiter RJ. Regulation of antioxidant enzymes: a significant role for melatonin. J Pineal Res. 2004;36(1):1-9.

24. Li H, He J, Yang X, Li X, Luo D, Wei C, Ma J, Zhang Y, Yang J, Zhang X. Glutathione-dependent induction of local and systemic defense against oxidative stress by exogenous melatonin in cucumber (Cucumis sativus L.). J Pineal Res. 2016;60(2):206-16.

25. Wang P, Yin L, Liang D, Li C, Ma F, Yue Z. Delayed senescence of apple leaves by exogenous melatonin treatment: toward regulating the ascorbate-glutathione cycle. J Pineal Res. 2012;53(1):11-20.

26. Wu J, Shu S, Li C, Sun J, Guo S. Spermidine-mediated hydrogen peroxide signaling enhances the antioxidant capacity of salt-stressed cucumber roots. Plant Physiol Biochem. 2018;128:152-62.

27. Gill SS, Tuteja N. Polyamines and abiotic stress tolerance in plants. Plant Signal Behav. 2010;5(1):26-33.

28. Ke Q, Ye J, Wang B, Ren J, Yin L, Deng X, Wang S. Melatonin mitigates salt stress in wheat seedlings by modulating polyamine metabolism. Front Plant Sci. 2018;9:914.

29. Groppa M, Benavides M. Polyamines and abiotic stress: recent advances. Amino Acids. 2008;34(1):35

30. Zhou C, Liu Z, Zhu L, Ma Z, Wang J, Zhu J. Exogenous melatonin improves plant iron deficiency tolerance via increased accumulation of polyaminemediated nitric oxide. Int J Mol Sci. 2016;17(11):1777.

31. Shi H, Jiang C, Ye T, Tan D-X, Reiter RJ, Zhang H, Liu R, Chan Z. Comparative physiological, metabolomic, and transcriptomic analyses reveal mechanisms of improved abiotic stress resistance in bermudagrass [Cynodon dactylon $(\mathrm{L})$. Pers.] by exogenous melatonin. J Exp Bot. 2014;66(3):681-94.

32. Lei XY, Zhu RY, Zhang GY, Dai YR. Attenuation of cold-induced apoptosis by exogenous melatonin in carrot suspension cells: the possible involvement of polyamines. J Pineal Res. 2004;36(2):126-31.

33. Cao S, Song C, Shao J, Bian K, Chen W, Yang Z. Exogenous melatonin treatment increases chilling tolerance and induces defense response in harvested peach fruit during cold storage. J Agric Food Chem. 2016; 64(25):5215-22.

34. Zhao H, Zhang K, Zhou X, Xi L, Wang Y, Xu H, Pan T, Zou Z. Melatonin alleviates chilling stress in cucumber seedlings by up-regulation of CsZat12 and modulation of polyamine and abscisic acid metabolism. Sc Rep. 2017:7(1):4998

35. Pál M, Szalai G, Janda T. Speculation: polyamines are important in abiotic stress signaling. Plant Sci. 2015;237:16-23.

36. Liang D, Gao F, Ni Z, Lin L, Deng Q, Tang Y, Wang X, Luo X, Xia H. Melatonin improves heat tolerance in kiwifruit seedlings through promoting antioxidant enzymatic activity and glutathione S-transferase transcription. Molecules. 2018;23(3):584.

37. Li H, Chang J, Chen H, Wang Z, Gu X, Wei C, Zhang Y, Ma J, Yang J, Zhang $X$. Exogenous melatonin confers salt stress tolerance to watermelon by improving photosynthesis and redox homeostasis. Front Plant Sci. 2017:8:295.

38. Zhao H, Ye L, Wang Y, Zhou X, Yang J, Wang J, Cao K, Zou Z. Melatonin increases the chilling tolerance of chloroplast in cucumber seedlings by regulating photosynthetic electron flux and the ascorbate-glutathione cycle. Front Plant Sci. 2016;7:1814.

39. Li C, Wang P, Wei Z, Liang D, Liu C, Yin L, Jia D, Fu M, Ma F. The mitigation effects of exogenous melatonin on salinity-induced stress in Malus hupehensis. J Pineal Res. 2012:53(3):298-306.

40. Pieri C, Marra M, Moroni F, Recchioni R, Marcheselli F. Melatonin: a peroxyl radical scavenger more effective than vitamin E. Life Sci. 1994; 55(15):PL271-6.

41. García JJ, López-Pingarrón L, Almeida-Souza P, Tres A, Escudero P, García-Gil FA, Tan DX, Reiter RJ, Ramírez JM, Bernal-Pérez M. Protective effects of melatonin in reducing oxidative stress and in preserving the fluidity of biological membranes: a review. J Pineal Res. 2014;56(3):225-37.

42. Liang D, Ni Z, Xia H, Xie Y, Lv X, Wang J, Lin L, Deng Q, Luo X. Exogenous melatonin promotes biomass accumulation and photosynthesis of kiwifruit seedlings under drought stress. Sci Hortic. 2019;246:34-43.

43. Hasan M, Ahammed GJ, Yin L, Shi K, Xia X, Zhou Y, Yu J, Zhou J. Melatonin mitigates cadmium phytotoxicity through modulation of phytochelatins biosynthesis, vacuolar sequestration, and antioxidant potential in Solanum lycopersicum L. Front Plant Sci. 2015;6:601.

44. Miller G, Mittler R. Could heat shock transcription factors function as hydrogen peroxide sensors in plants? Ann Bot. 2006;98(2):279-88. 
45. Katano K, Honda K, Suzuki N. Integration between ROS regulatory systems and other signals in the regulation of various types of heat responses in plants. Int J Mol Sci. 2018;19(11):3370.

46. Driedonks N, Xu J, Peters JL, Park S, Rieu I. Multi-level interactions between heat shock factors, heat shock proteins, and the redox system regulate acclimation to heat. Front Plant Sci. 2015;6:999.

47. Manchester LC, Coto-Montes A, Boga JA, Andersen LPH, Zhou Z, Galano A Vriend J, Tan DX, Reiter RJ. Melatonin: an ancient molecule that makes oxygen metabolically tolerable. J Pineal Res. 2015;59(4):403-19.

48. Reiter RJ, Mayo JC, Tan DX, Sainz RM, Alatorre-Jimenez M, Qin L. Melatonin as an antioxidant: under promises but over delivers. J Pineal Res. 2016;61(3):253-78.

49. Arnao MB, Hernández-Ruiz J. Functions of melatonin in plants: a review. J Pineal Res. 2015:59(2):133-50

50. Reiter R, Tan D-X, Zhou Z, Cruz M, Fuentes-Broto L, Galano A. Phytomelatonin: assisting plants to survive and thrive. Molecules. 2015; 20(4):7396-437

51. Hardeland R. Melatonin in plants and other phototrophs: advances and gaps concerning the diversity of functions. J Exp Bot. 2014;66(3):627-46.

52. Nawaz MA, Jiao Y, Chen C, Shireen F, Zheng Z, Imtiaz M, Bie Z, Huang Y. Melatonin pretreatment improves vanadium stress tolerance of watermelon seedlings by reducing vanadium concentration in the leaves and regulating melatonin biosynthesis and antioxidant-related gene expression. J Plant Physiol. 2018;220:115-27.

53. Alscher RG, Erturk N, Heath LS. Role of superoxide dismutases (SODs) in controlling oxidative stress in plants. J Exp Bot. 2002:53(372):1331-41.

54. Mittler R. Oxidative stress, antioxidants and stress tolerance. Trends Plant Sci. 2002; 7(9):405-10

55. Li X, Brestic M, Tan DX, Zivcak M, Zhu X, Liu S, Song F, Reiter RJ, Liu F. Melatonin alleviates low PS I-limited carbon assimilation under elevated CO 2 and enhances the cold tolerance of offspring in chlorophyll b-deficient mutant wheat. J Pineal Res. 2018;64(1):e12453.

56. Meng JF, Xu TF, Wang ZZ, Fang YL, Xi ZM, Zhang ZW. The ameliorative effects of exogenous melatonin on grape cuttings under water-deficient stress: antioxidant metabolites, leaf anatomy, and chloroplast morphology. J Pineal Res. 2014;57(2):200-12.

57. Ding F, Liu B, Zhang S. Exogenous melatonin ameliorates cold-induced damage in tomato plants. Sci Hortic. 2017;219:264-71.

58. Noctor $\mathrm{G}$, Foyer $\mathrm{CH}$. Ascorbate and glutathione: keeping active oxygen under control. Annu Rev Plant Biol. 1998;49(1):249-79.

59. Bonnefont-Rousselot D, Collin F, Jore D, Gardès-Albert M. Reaction mechanism of melatonin oxidation by reactive oxygen species in vitro. Pineal Res. 2011;50(3):328-35.

60. Maresca $V$, Sorbo S, Keramat B, Basile A. Effects of triacontanol on ascorbate -glutathione cycle in Brassica napus L. exposed to cadmium-induced oxidative stress. Ecotoxicol Environ Saf. 2017;144:268-74.

61. Wang P, Sun X, Li C, Wei Z, Liang D, Ma F. Long-term exogenous application of melatonin delays drought-induced leaf senescence in apple. J Pineal Res. 2013;54(3):292-302.

62. Zheng X, Tan DX, Allan AC, Zuo B, Zhao Y, Reiter RJ, Wang L, Wang Z, Guo $Y$, Zhou J. Chloroplastic biosynthesis of melatonin and its involvement in protection of plants from salt stress. Sci Rep. 2017:7:41236.

63. Zhan H, Nie X, Zhang T, Li S, Wang X, Du X, Tong W, Song W. Melatonin: a small molecule but important for salt stress tolerance in plants. Int J Mol Sci. 2019;20(3):709

64. Zhang Q, Liu X, Zhang Z, Liu N, Li D, Hu L. Melatonin improved waterlogging tolerance in alfalfa (Medicago sativa) by reprogramming polyamine and ethylene metabolism. Front Plant Sci. 2019;10:44.

65. Alam MN, Zhang L, Yang L, Islam MR, Liu Y, Luo H, Yang P, Wang Q, Chan Z. Transcriptomic profiling of tall fescue in response to heat stress and improved thermotolerance by melatonin and 24-epibrassinolide. BMC Genomics. 2018;19(1):224

66. Gupta KJ, Fernie AR, Kaiser WM, van Dongen JT. On the origins of nitric oxide. Trends Plant Sci. 2011;16(3):160-8

67. Rosales EP, lannone MF, Groppa MD, Benavides MP. Polyamines modulate nitrate reductase activity in wheat leaves: involvement of nitric oxide. Amino Acids. 2012:42(2-3):857-65.

68. Shi H, Chan Z. Improvement of plant abiotic stress tolerance through modulation of the polyamine pathway. J Integr Plant Biol. 2014;56(2): 114-21.

69. Martinez V, Nieves-Cordones M, Lopez-Delacalle M, Rodenas R, Mestre T, Garcia-Sanchez F, Rubio F, Nortes P, Mittler R, Rivero R. Tolerance to stress combination in tomato plants: new insights in the protective role of melatonin. Molecules. 2018;23(3):535.

70. Shi J, Fu X-Z, Peng T, Huang X-S, Fan Q-J, Liu J-H. Spermine pretreatment confers dehydration tolerance of citrus in vitro plants via modulation of antioxidative capacity and stomatal response. Tree Physiol. 2010;30(7):914-22.

71. Velikova V, Yordanov I, Edreva A. Oxidative stress and some antioxidant systems in acid rain-treated bean plants: protective role of exogenous polyamines. Plant Sci. 2000;151(1):59-66.

72. Nahar K, Hasanuzzaman M, Alam MM, Fujita M. Exogenous glutathione confers high temperature stress tolerance in mung bean (Vigna radiata L.) by modulating antioxidant defense and methylglyoxal detoxification system. Environ Exp Bot. 2015;112:44-54.

73. Alexieva V, Sergiev I, Mapelli S, Karanov E. The effect of drought and ultraviolet radiation on growth and stress markers in pea and wheat. Plant Cell Environ. 2001:24(12):1337-44.

74. Bates LS, Waldren RP, Teare I. Rapid determination of free proline for water -stress studies. Plant Soil. 1973;39(1):205-7.

75. Barrs $\mathrm{H}$, Weatherley P. A re-examination of the relative turgidity technique for estimating water deficits in leaves. Aust J Biol Sci. 1962;15(3):413-28.

76. Giannopolitis CN, Ries SK. Superoxide dismutases: I. Occurrence in higher plants. Plant Physiol. 1977;59(2):309-14.

77. Nickel KS, Cunningham B. Improved peroxidase assay method using leuco 2, 3', 6-trichloroindophenol and application to comparative measurements of peroxidatic catalysis. Anal Biochem. 1969;27(2):292-9.

78. Dhindsa RS, Plumb-Dhindsa PL, Reid DM. Leaf senescence and lipid peroxidation: effects of some phytohormones, and scavengers of free radicals and singlet oxygen. Physiol Plant. 1982;56(4):453-7.

79. Nakano Y, Asada K. Hydrogen peroxide is scavenged by ascorbate-specific peroxidase in spinach chloroplasts. Plant Cell Physiol. 1981;22(5):867-80.

80. Logan BA, Demmig-Adam B, Adams WW III. Antioxidants and xanthophyll cycle-dependent energy dissipation in Cucurbita pepo L. and Vinca major L. upon a sudden increase in growth PPFD in the field. J Exp Bot. 1998:49(328):1881-8.

81. Griffith OW. Determination of glutathione and glutathione disulfide using glutathione reductase and 2-vinylpyridine. Anal Biochem. 1980;106(1):207-12

82. Hossain MA, Nakano Y, Asada K. Monodehydroascorbate reductase in spinach chloroplasts and its participation in regeneration of ascorbate for scavenging hydrogen peroxide. Plant Cell Physiol. 1984;25(3):385-95.

83. Bradford MM. A rapid and sensitive method for the quantitation of microgram quantities of protein utilizing the principle of protein-dye binding. Anal Biochem. 1976;72(1-2):248-54.

84. Shen J-I, Wang Y, Shu S, Jahan MS, Zhong M, Wu J-q, Sun J, Guo S-r. Exogenous putrescine regulates leaf starch overaccumulation in cucumber under salt stress. Sci Hortic. 2019:253:99-110.

85. Wang Y, Cai SY, Yin LL, Shi K, Xia XJ, Zhou YH, Yu JQ, Zhou J. Tomato HsfA1a plays a critical role in plant drought tolerance by activating ATG genes and inducing autophagy. Autophagy. 2015;11(11):2033-47.

\section{Publisher's Note}

Springer Nature remains neutral with regard to jurisdictional claims in published maps and institutional affiliations.

Ready to submit your research? Choose BMC and benefit from:

- fast, convenient online submission

- thorough peer review by experienced researchers in your field

- rapid publication on acceptance

- support for research data, including large and complex data types

- gold Open Access which fosters wider collaboration and increased citations

- maximum visibility for your research: over $100 \mathrm{M}$ website views per year

At BMC, research is always in progress.

Learn more biomedcentral.com/submissions 